\title{
Persistence Through Function Preservation
}

[forthcoming in Synthese]

David Rose

How do ordinary material objects persist? For instance, if a rock is hit with a hammer and chipped, does the rock survive? Or if a rock is smashed to pieces by a hammer, does the rock survive the smashing? Many metaphysicians have wanted a view of persistence that fits with folk intuitions and have charged leading views with failing to do so. Yet, there is disagreement about what the folk intuit and no empirical discipline to the discussion. For a debate so heavily centered on folk intuitions, it seems that some empirical evidence might help advance the discussion. Indeed, it seems that empirically discerning the folk view of persistence will help decide whether it deserves to be taken seriously.

So my question is: what is the folk view of persistence against which metaphysical accounts might be measured? My view is that the folk view of persistence is teleological in that the folk tend to intuit that a material object survives alterations when its function is preserved. As such, I hold that the folk view of persistence is tied into a benighted view of nature and thus deserves to be dismissed. Given an empirically informed understanding of the folk view of persistence, I hold that the discussion over how ordinary objects persist should be liberated from any demanded conformity with folk intuitions.

The Plan: I'll begin, in Section I, by briefly documenting some conflicting claims about the folk view of persistence and charges of failing to fit common sense. In Section II, I will present evidence from psychology which suggests that the folk are promiscuous teleologists. Given the background of promiscuous teleology, I will then go on, in Section III, to present a range of evidence in support of the claim that the folk view of persistence is teleological. Having achieved sufficient empirical understanding of the folk view of persistence to judge its credentials, I will, in Section IV, argue for a dismissive take on folk intuitions about material object persistence. I will situate the discussion within the background of what Dan Korman (2009) calls the challenge from folk belief and discuss my results in the context of debunking arguments in order to show how the challenge can be met, concluding that in the specific case of persistence, the folk do not deserve to be taken seriously. They deserve to be ignored.

\section{Persistence and Common Sense}

How do ordinary material objects persist? There are two general answers. The first is the answer of the four dimensionalist. According to the four dimensionalist, ordinary material objects persist by having temporal parts, in addition to spatial parts, which are spread out across regions of spacetime. Ordinary objects persist by having distinct temporal parts at more than one time: they persist by perduring. The second answer, that of the three dimensionalist, denies that ordinary material objects persist by having temporal parts. Instead, the three dimensionalist holds that ordinary material objects persist by being "wholly present" at more than one time, 
sweeping across spacetime with the whole of the object occupying different regions at different times. ${ }^{1}$ Ordinary objects persist by enduring.

The four dimensionalists view of how ordinary material objects persist is typically charged with being "wildly counterintuitive" (Sider, 2001, p.3), "radically at odds with common sense" (Paul, 2002, p. 587), and "crazy metaphysics" (Thomson, 1983, p. 213). Three dimensionalists typically claim that their view better fits "common sense" (e.g., Merricks, 1994, p. 165; Paul, 2002, p. 586; Wiggins, 1980, p. 25). But four dimensionalists often dispute the charges. Some have suggested that "it is not clear that common sense offers any direct verdict" (Hawthorne, 2008, p. 3) against four dimensionalism, having never considered the question of whether ordinary objects have temporal parts (see also Benovsky, 2006). Indeed it has been suggested that "even though it is at first glance counterintuitive, [four dimensionalism] becomes more palatable even for common sense once one thinks more about it". And so having thought more about four dimensionalism, the folk will come to see that it's "the competing views that suffer from counterintuitive consequences" (Benovsky, 2006, p. 104).

So, we see a dispute between three and four dimensionalists about whether the three or four dimensionalist view of how ordinary objects persist fits with common sense. Does three dimensionalism better fit with common sense? Or rather would the folk, after having thought sufficiently about four dimensionalism, come to view it as more palatable, thinking that it's the competing three dimensionalist conception which suffers from being counterintuitive?

Aside from the dispute over whether the common sense view of how ordinary objects persist better fits with three or four dimensionalism, we also see a dispute over the common sense view of persistence in connection with one of the most standard accounts of persistence: the sortal based account (e.g., Wiggins, 1980; Hirsh, 1982; Lowe 1995).

Sortal based accounts hold that we trace the career of ordinary objects by tracing under a sortal. Sortals, on this view, answer the question of "what is it" and determine the persistence conditions for objects falling under the sortal. Many who hold a sortal based view allow that material objects can coincide. For instance, a statue and lump of copper can occupy exactly the same place at the same time and yet remain numerically distinct. The reason why, according to this account, is because the copper and statue fall under different sortals and accordingly have different persistence conditions associated with them. The statue, if pounded by a hammer, would not survive; yet the copper could survive being pounded by a hammer. So according to this account, coincidence can occur among objects that belong to different kinds (Wiggins, 1968).

Though the sortal based account has been recommended for fitting common sense, the account has also been charged with violating common sense. Burke (1997) recommends the standard sortal based account since it is "consisten[ $\mathrm{t}]$ ] with the metaphysics implicit in ordinary ways of thinking" (p. 11). But, Burke continues, "There is one consequence of the standard account that many have found uncongenial, if not intolerable: that it is possible, indeed common, for one

\footnotetext{
${ }^{1}$ I will, along with others (e.g., Hawley, 2001, Lewis, 1986, Sider, 2001), take one of the main distinguishing features of three and four dimensionalism to be the acceptance of temporal parts (though see Parsons, 2000).
} 
object to coincide with another" (p. 11). Burke holds that this is "at odds with commonsense" and thus avoids coincidence by arguing that a piece of copper is destroyed upon being fashioned into a statue. In its place there comes to exist a new piece of cooper, which is identical to the resultant statue.

But Lowe (1995) claims, "it most certainly is...contrary to common sense to claim that a piece of copper must cease to exist merely upon assuming a certain shape — as any seven-year old child will confirm, if the question is put to him in terms of the fate of a piece of plasticene which is fashioned into the figure of a man.... I would most strenuously deny that his position is more in keeping with common sense than the standard account can claim to be" (1995, p. 176). Burke (1994), however, disputes the charges, claiming that once the distinction between the original lump and piece of copper is made clear, we see that it "is not the violation of common sense it initially seems" (p. 598)

Fit with common sense is an important desideratum in disputes over persistence. ${ }^{2}$ Three dimensionalists tend to claim that their view fits better with common sense; four dimensionalists dispute the charges, claiming that their view fits common sense. And the standard sortal based account has been recommended for its (apparent) fit with common sense. But if fit with common sense is to serve as a desideratum in theory choice, then it seems that a precondition for deciding whether common sense is a good metric is determining what the folk view is and whether it deserves to be taken seriously. And empirical evidence on the folk view can help in deciding whether the measure of common sense, in specific domains, is a good measure. By empirically discerning what the folk view is in a specific domain, one is thereby in a position to decide whether measuring a metaphysical theory by its fit with the specific folk view under consideration is a wise policy.

My view is that the folk view of persistence is teleological and as such I see the view as being fit for dismissal in the debate over persistence. But before getting on to my own studies in support of the hypothesis that the folk view of persistence is teleological, I want to first briefly motivate the hypothesis by situating it within a background discussion of promiscuous teleology.

\section{Psychological Background on Folk Teleology}

\subsection{Selective Teleology}

It's widely agreed that we're at least selective teleologists in that our artifact and organism concepts are infused with considerations of purpose and function. Most work supporting this has come from studies investigating principles of object categorization (what a thing is) with the general result being that we tend to determine what a thing is by determining what it is for (what is its purpose).

With artifact concepts, German \& Johnson (2002) note that it is well established that people take "the design stance, in which an entity's properties, behavior, and existence is explained in terms of its having been designed to serve a particular purpose" (pp. 279-280). Likewise Bloom

\footnotetext{
${ }^{2}$ I've only offered a brief sampling of disputes over the common sense view of persistence. For more, see the excellent discussion in Sidelle (2002).
} 
(1996), reviewing earlier work by Rips and by Keil, notes: "This has suggested to many scholars that the psychological 'core' of artifact concepts is that their members share a common intended function" (p. 63).

As with artifact concepts, it is also agreed that our organism concepts are infused with teleological considerations. For example, Frank Keil (1995) writes:

Historically there have been many arguments for a 'design' stance, which can include teleological interpretations and tool construction and use... Notions of functional architecture are among the most cognitively compelling ways of approaching the biological world and much of the artificial world as well.... (p. 245)

In a similar vein, Atran (1998) speaks of the folk idea of a "biological essence" as "an intrinsic...teleological agent, which physically... causes the biologically relevant parts and properties of a generic species to function and cohere 'for the sake of' the generic species itself" (pp. 550-551).

\subsection{Promiscuous Teleology}

Though it is widely agreed that we're at least selective teleologists in that our artifact and organism concepts are infused with teleological considerations, Kelemen (1999) suggests that the more psychologically plausible view is that of promiscuous teleology. On this view, teleological considerations not only influence our conception of artifacts and organism but also affect our general conception of an object and extend to even non-living natural things like rocks. She writes:

[T] hroughout history, non-living natural objects have...been considered in... [teleological] terms... The earth, its climates, landforms, water sources, and elements, were seen as intentionally designed to create a habitat for, and meet the needs of, people. In other words, natural objects of all kinds - particularly those fulfilling a significant function in people's lives_-were candidates for construal as quasi-artifacts. (p. 245)

Though there is a range of evidence supporting the view that children are promiscuous teleologists (e.g., Kelemen and Diyanni, 2005; Kelemen, 1999a, 1999b, 2004), other work suggests that even adults never fully outgrow their childhood tendencies toward promiscuous teleology (e.g., Kelemen and Rosset, 2009; Kelemen, Rottman and Seston, 2013; Lombrzo, Kelemen and Zaitchick, 2007). For instance, Kelemen and Rossett (2009) found that even college aged students revert to unwarranted teleological explanations, even in scientific contexts, in conditions where their cognitive resources are limited. Similarly, Kelemen et al (2013) also found that even trained physical scientist show a similar pattern of reverting to unwarranted teleological explanations in similar conditions.

Indeed, recent work by Rose and Schaffer (2014), investigating the role of teleological considerations in ordinary intuitions about mereological composition, provides evidence that the folk tend to intuit that a plurality has a fusion when the result has a purpose. In a wide range of cases, they found that the folk tended to judge that the plurality composed a further object when the result had a purpose and that the folk tended to judge that the plurality did not compose a 
further object when the result did not have a purpose. They found this basic pattern for cases involving artifacts, organisms and non-living natural objects like rocks. The background psychological literature on promiscuous teleology and principles of object categorization suggests that what something is (sortal) is given by what function it has; the results from Rose and Schaffer suggest that whether something is (whether this is a fusion) is determined by whether there is a function. Extending this pattern to the folk view of persistence: whether something persists is given by whether it continues to serve its function.

\section{The Folk View of Persistence}

I'll begin with gradual-replacement-of-parts cases, examining whether teleological considerations influence ordinary judgments about persistence for artifacts, organisms and rocks undergoing gradual part replacement. Having done this, I'll move away from gradualreplacement-of-parts cases and look at cases where a rock is hit with a hammer. The reason for considering diverse cases is twofold. First, by considering a range of different cases, I hoped that the results might prove to be robust. As it turns out, this is the case. Across a range of cases, it turns out that a consistent pattern emerges: folk intuitions about material object persistence are largely driven by teleological considerations. Second, even though any single study may be questioned and open to diverse interpretations, by considering a range of different cases, I hoped that a consistent pattern would emerge. The overall pattern that appears to emerge is that the folk operate with a teleological view of persistence. That said, the results below, as with any empirical work, are defeasible in light of future inquiry. I take this to be the first, though not the last, word on the folk view of persistence and encourage further empirical work.

\subsection{Gradual Replacement: Rowboat, Organism and Rock}

I created three different cases — involving a rowboat, an organism, and a rock ${ }^{3}$ — and for each case varied whether the replacement object or the object with the original parts preserved the function of the original object or whether no function was mentioned at all. For each caserowboat, organism and rock - there were three conditions: No Function, Replacement Preserves Function and Original Parts Preserves Function.

The rowboat cases were modeled after the classic "Ship of Theseus" cases. In the No Function version, participants were told about John, a woodworker and sailor, who built his first rowboat "Drifter" thirty years ago. Over the years there was wear and tear on the boat and he eventually replaced all of the original planks with new planks. He kept all of the original planks and one day constructed a rowboat with them.

In both the Replacement Preserves Function version and the Original Parts Preserves Function version, participants were told that the original rowboat that John built was excellent and functioned perfectly as a rowboat. They were then told that either Replacement or Original Parts continued to function perfectly. After reading the stories, participants were told that two people - Andy and Suzy — wanted to borrow "Drifter" for an outing and disagreed about which

\footnotetext{
${ }^{3}$ For full cases, see Appendix.
} 
boat is "Drifter". In all cases, Andy thinks that original parts is "Drifter" while Suzy thinks that replacement is "Drifter". Participants were asked to indicate the extent to which they agreed with Andy or Suzy, on a 7-pt scale anchored with 1=Suzy is right and 7-Andy is right.

The organism cases were similar to the rowboat cases. In the No Function case, participants were told that John discovered a new organism, which he named "Gollywag". Over the years, John experiments with it and each time he does, he removes a part from it and replaces it with a new part from the same type of organism until it has completely new parts. He keeps all of the original parts and one day assembles them.

In the function versions, participants were told that John suffered from eczema and that when handling the original organism he noticed that his eczema started to disappear. In one version, the Replacement preserved the function of relieving John's eczema while in the other, Original Parts preserved the function of relieving John's eczema. In all cases, participants were told that Andy and Suzy are interns, given the job of experimenting on "Gollywag". But Andy and Suzy disagree over whichobject is "Gollywag". Participants indicated the extent to which they agreed with Andy or Suzy on the same seven point scale used in the rowboat case.

The final case involved a rock. In the No Function case, John found a new rock which he named "Zenyte". Over the years, he experiments with the rock and each time he conducts an experiment he breaks off a piece of the rock and replaces it with a new part from the same type of rock until it has completely new parts. He keeps all of the original parts and one day assembles them.

As in the organism cases, in the function versions, participants were told that John suffered from eczema and that when handling the original rock he noticed that his eczema started to disappear. In one version, the Replacement preserved the function of relieving John's eczema while in the other, Original Parts preserved the function of relieving John's eczema. As in the organism cases, Andy and Suzy are given the job of experimenting on "Zenyte" but disagree about which object is "Zenyte". As in the other cases, participants indicated the extent to which they agreed with Andy or Suzy on the same seven point scale.

The results indicated that whether or not Replacement or Original Parts preserved the function of the original object had a strong effect on people's persistence judgments. And this effect was present, regardless of the type of object that underwent gradual part replacement, as can be seen in the images below: ${ }^{4}$

\footnotetext{
${ }^{4}$ A total of 330 participants were recruited from Amazon's Mechanical Turk. Participants were randomly assigned to one of nine conditions in a 3 (Function: None, Replacement Preserves Function, Original Parts Preserves Function) x 3 (Object Type: Rowboat, Organism, Rock) design. After reading the case, participants rated the extent to which they agreed with either Andy or Suzy. They were then taken to a separate screen where they were asked comprehension questions (see appendix for details). 10 people were excluded from the data analysis for missing one or more comprehension questions, leaving a total of 320 responses. The results indicated that there was a largesized effect of Function, $\mathrm{F}(2,311)=33.568$, $\mathrm{p}<.001, \eta \mathrm{p}^{2}=.178$; no effect of Object Type, $\mathrm{F}(2,311)=2.832$, $\mathrm{p}>.05$; and no interaction between Function and Type of Object, F(4,311)=258, p>.05.

Rowboat: Planned pairwise comparisons in the Rowboat condition revealed a large-sized significant difference between Replacement Preserves Function $(\mathrm{M}=2.79, \mathrm{SD}=1.77)$ and Original Parts Preserves Function
} 

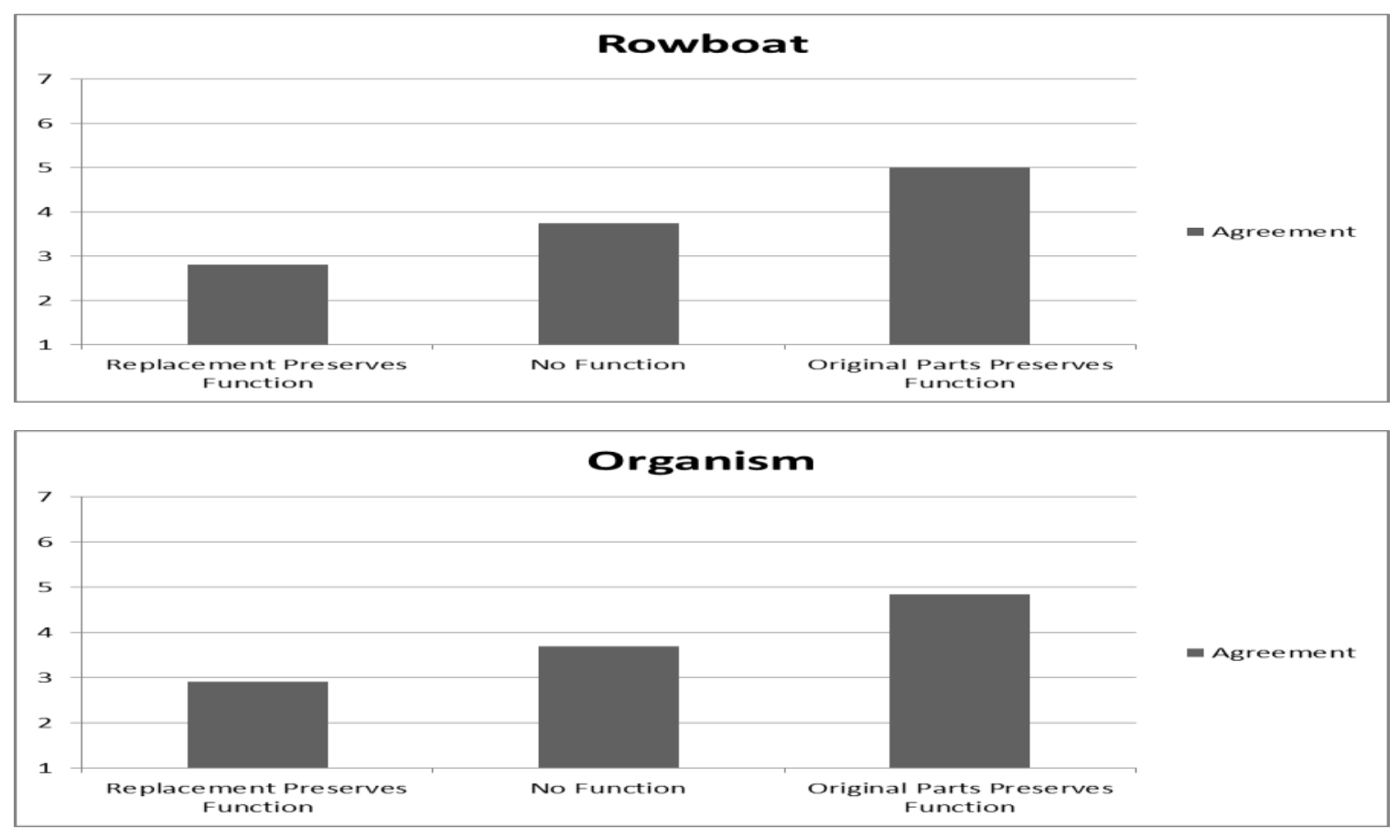

$(\mathrm{M}=5.03, \mathrm{SD}=2.22), \mathrm{t}(67)=4.60, \mathrm{p}<.001, \mathrm{~d}=1.11$; a medium-sized significant difference between No Function $(\mathrm{M}=3.75, \mathrm{SD}=2.06)$ and Original Parts Preserves Function, $\mathrm{t}(68)=2.50, \mathrm{p}<.01, \mathrm{~d}=.61$; and a medium-sized significant difference between No Function and Replacement Preserves Function, $\mathrm{t}(67)=2.04, \mathrm{p}<.05, \mathrm{~d}=.50$.

Organism: Planned pairwise comparisons in the Organism condition revealed a large-sized significant difference between Replacement Preserves Function $(\mathrm{M}=2.94, \mathrm{SD}=1.63)$ and Original Parts Preserves Function $(\mathrm{M}=4.81, \mathrm{SD}=1.95), \mathrm{t}(72)=4.45, \mathrm{p}<.001, \mathrm{~d}=1.04$; a medium-sized significant difference between No Function $(\mathrm{M}=3.72, \mathrm{SD}=2.09)$ and Original Parts Preserves Function, $\mathrm{t}(67)=2.24, \mathrm{p}<.05, \mathrm{~d}=.54$; and a small-sized marginally significant difference between No Function and Replacement Preserves Function, $\mathrm{t}(67)=1.72, \mathrm{p}=.09, \mathrm{~d}=.41$.

Rock: Planned pairwise comparisons in the Rock condition revealed a large-sized significant difference between Replacement Preserves Function $(\mathrm{M}=3.27, \mathrm{SD}=2.06)$ and Original Parts Preserves Function $(\mathrm{M}=5.75$, $\mathrm{SD}=1.81), \mathrm{t}(71)=5.45, \mathrm{p}<.001, \mathrm{~d}=1.28$; a large-sized significant difference between No Function $(\mathrm{M}=4.16, \mathrm{SD}=2.12)$ and Original Parts Preserves Function, $\mathrm{t}(71)=3.43, \mathrm{p}<.01, \mathrm{~d}=.81$; and a small-sized marginally significant difference between No Function and Replacement Preserves Function, t(72)=1.83, p=.07, d=.43.

Throughout, I will be reporting effect sizes for significant effects. I'll be reporting partial Eta squared $\left(\eta p^{2}\right)$ and Cohen's d. $\eta p^{2}$ indicates the amount of variance in the dependent variable explained by a given independent variable while Cohen's d indicates the magnitude of the mean difference between two groups. I'll follow Ellis (2010) for interpreting the magnitude of effect sizes. For $\eta p^{2} I^{\prime} l 1$ interpret values greater than or equal to .14 as large, greater than or equal to .06 but less than .14 as medium, and greater than or equal to .01 but less than .06 as small. And for Cohen's d I'll interpret values greater than or equal to .8 as large, greater than or equal to .5 but less than .8 as medium, and greater than or equal to .2 but less than .5 as small. 


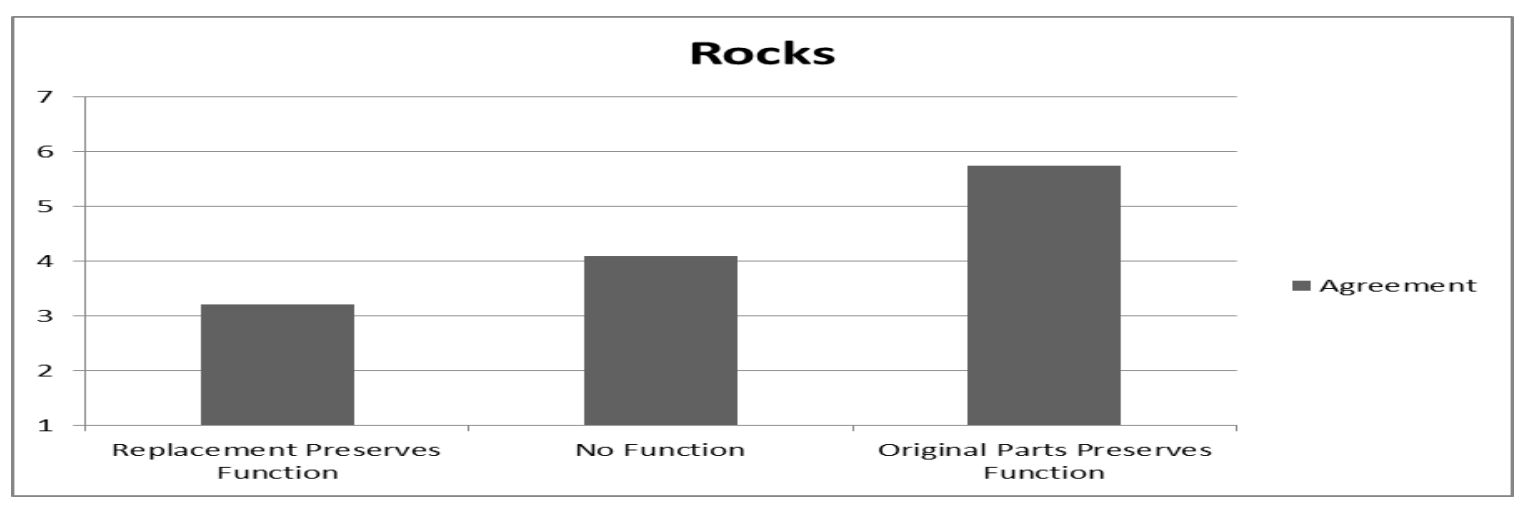

Though it is perhaps natural to think that teleological considerations should play a role in determining whether artifacts or organisms persist (e.g., Wiggins, 1980; Hirsh, 1982; Van Inwagen, 1990), the above results indicate that teleological considerations play a role in persistence judgments for non-living natural objects like rocks. As far as I am aware, no metaphysician has ever suggested that teleological considerations should or even expected that teleological considerations would play a role in folk persistence judgments for non-living natural objects like rocks. But, against a background of promiscuous teleology, these results are perhaps unsurprising. These initial results fit with the view that we are promiscuous teleologists and suggest that teleological considerations even infuse our judgments about whether ordinary material objects persist.

Though these initial results begin to suggest that the folk operate with a teleological view of persistence, there are two natural concerns with the above studies. The first is that, instead of this pattern of judgments suggesting that the folk view is teleological, a better explanation of this pattern of findings is that the folk are merely operating on the assumption that John, in the rowboat case for example, is not a jerk and so would only lend a rowboat that worked. So, perhaps the pattern of judgments in the rowboat case has nothing to do with teleology but rather is better explained on the natural assumption that people's judgments track the functioning rowboat since they assume that John would not lend a broken rowboat to his friends. And similarly, for the organism and rock cases, perhaps it's natural to think that John cares about whether the organism or rock continues to function and so wouldn't assign Suzy and Andy to experiment with the non-functioning object. So perhaps these considerations better explain the pattern of judgments found above.

A second concern with the above studies pertains to the organism and rock cases. In both of those cases, the relevant function specifically benefitted John. Perhaps in a suitably modified story, where the relevant function didn't benefit people whatsoever, teleological considerations would cease to play a role in ordinary persistence judgments. Such a finding would be interesting in its own right since it would suggest that there is an interesting restriction on the type of function that ends up playing a role in folk persistence judgments. The next set of studies takes up both of these concerns. 


\subsection{Gradual Replacement: Rowboat, Organism and Rock Modified}

To address the concern that in the rowboat cases the pattern of judgments is better explained by participants assuming that John would not lend a broken rowboat, I modified the cases so that rather than wanting to borrow the rowboat for an outing, Andy and Suzy want to paint a portrait of the rowboat. Thus, the stories were similar to the ones above except participants were told that Andy and Suzy wanted to paint a portrait of the rowboat for an art class they were taking. John told them, over the phone, that they could paint "Drifter" and told them that he would be out of town and would have no phone or internet access. Participants were given a No Function version and a Replacement and Original Parts Preserves Function versions (for details, see Appendix).

To address the concerns about the Organism and Rock cases, I did two things. First, to address the concern that the pattern of judgments found in Study 1 is better explained by participants assuming John would not assign his interns to experiment with a non-functioning object, I had John explicitly say that he did not care about the function of the object. Second, to address the concern that the pattern of judgments observed in Study 1 was only due to the object having a purpose for humans, I altered the function of the objects so that it did not benefit humans whatsoever.

So, in the Organism case, participants were told that John discovered a new microorganism, "Gollywag". In the No Function version, John disassembled it over the years and replaced parts from the same type of microorganism. When he had accumulated enough of the original parts, he fashioned them into a microorganism which was exactly like the replacement.

In both the Replacement and Original Parts versions, participants were told that John gave the microorganism to his friend, Frank, who is a biochemist, to examine. Frank keeps the microorganism for several days and tells John that the microorganism is very delicate and must maintain a body temperature between 60 and 65 degrees. To maintain its temperature, it emits a unique sequence of chemicals that signal other microorganisms to group around it and heat it up. But John isn't interested in the chemicals emitted by the microorganism. Rather he is only interested in investigating and studying the various parts of the microorganism. So, John experiments with the microorganism, eventually replacing all of its parts and later assembles the original parts into a microorganism which is exactly like the replacement.

Function was varied by either having the Replacement preserve the function of the original by continuing to emit the chemicals or by having Original Parts preserve the function of the original by continuing to emit the chemicals. At the end of the stories participants were told that John gave two of his interns, Andy and Suzy, the job of experimenting on "Gollywag" (see Appendix).

The Rock cases were similar to the Organism cases, except that the rock had a different function: it created a perfectly hospital environment for some worms. In addition to a No Function version, participants were given a version where the Replacement preserved the function of the original or Original Parts preserved the function of the original. As in the Organism case, John assigns two interns, Andy and Suzy, the job of experimenting on "Zenyte". In this as well as the 
other cases, Andy and Suzy disagreed over which object was the original. Participants, in all versions, indicated who they agreed with on the same seven point scale that was used in the first study (see Appendix).

As with first study, the results continued to suggest that the folk operate with a teleological view of persistence in that they tend to intuit that an object persist when it preserves its function. ${ }^{5}$ The results are shown in the following images:

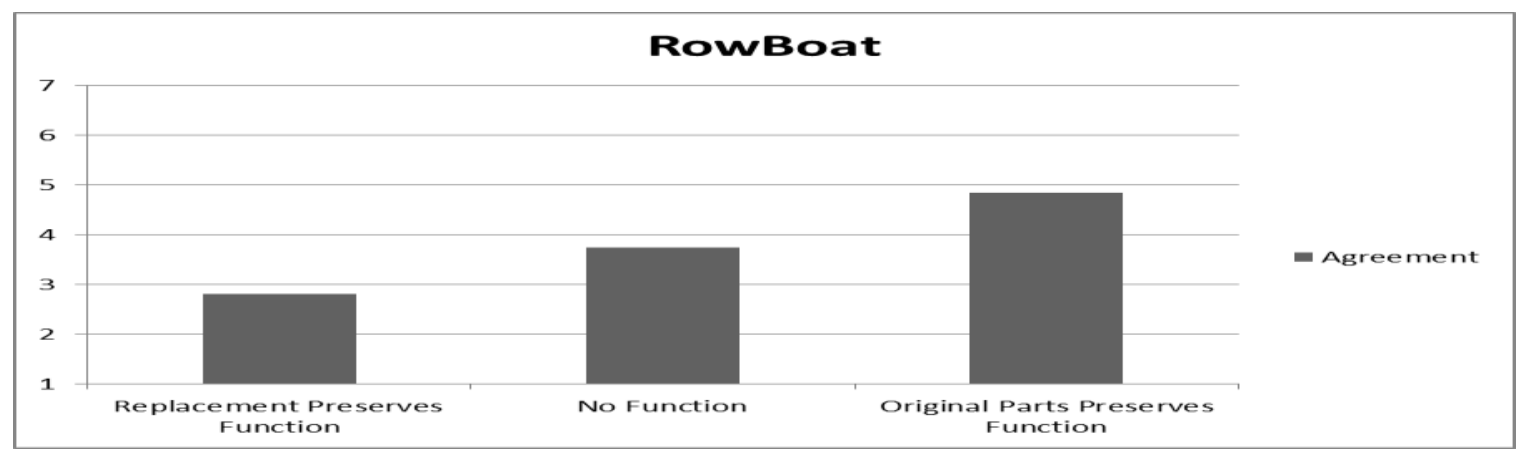

\footnotetext{
${ }^{5}$ A total of 310 participants were recruited from Amazon's Mechanical Turk. Participants were randomly assigned to one of nine conditions in a 3 (Function: None, Replacement Preserves Function, Original Parts Preserves Function) x 3 (Object Type: Rowboat, Organism, Rock) design. After reading the case, participants rated the extent to which they agreed with either Andy or Suzy. They were then taken to a separate screen where they were asked comprehension questions (see appendix for details). 13 people were excluded from the data analysis for missing one or more comprehension questions, leaving a total of 297 responses. The results indicated that there was a largesized effect of Function, $\mathrm{F}(2,288)=34.475$, $\mathrm{p}<.001, \eta \mathrm{p}^{2}=.193$; no effect of Object Type, $\mathrm{F}(2,288)=2.592$, p >.05; and no interaction between Function and Type of Object, F(4, 288)=.088, p>.05.

Rowboat: Planned pairwise comparisons in the Rowboat condition revealed a large-sized significant difference between Replacement Preserves Function (M=2.78, SD=2.01) and Original Parts Preserves Function $(\mathrm{M}=4.85, \mathrm{SD}=1.91), \mathrm{t}(64)=4.27, \mathrm{p}<.001, \mathrm{~d}=1.05$; a medium-sized significant difference between No Function $(M=3.74, S D=2.16)$ and Original Parts Preserves Function, $t(65)=2.50, p<.05, d=.55$; and a small-sized marginally significant difference between No Function and Replacement Preserves Function, t(65)=1.85, p=.07, d=.46.

Organism: Planned pairwise comparisons in the Organism condition revealed a large-sized significant difference between Replacement Preserves Function ( $\mathrm{M}=3.15, \mathrm{SD}=1.82)$ and Original Parts Preserves Function $(\mathrm{M}=5.57, \mathrm{SD}=1.65), \mathrm{t}(66)=5.75, \mathrm{p}<.001, \mathrm{~d}=1.39$; a medium-sized significant difference between No Function $(\mathrm{M}=4.37, \mathrm{SD}=2.06)$ and Original Parts Preserves Function, $\mathrm{t}(68)=2.69, \mathrm{p}<.01, \mathrm{~d}=.64$; and a medium-sized significant difference between No Function and Replacement Preserves Function, t(66)=2.58, p<.05, d=.63.

Rock: Planned pairwise comparisons in the Rock condition revealed a large-sized significant difference between Replacement Preserves Function $(\mathrm{M}=3.10, \mathrm{SD}=1.78)$ and Original Parts Preserves Function $(\mathrm{M}=5.39$, $\mathrm{SD}=1.66), \mathrm{t}(59)=5.17, \mathrm{p}<.001, \mathrm{~d}=1.32$; a medium-sized significant difference between No Function $(\mathrm{M}=4.27$, $\mathrm{SD}=1.89$ ) and Original Parts Preserves Function, $\mathrm{t}(62)=2.49, \mathrm{p}<.05, \mathrm{~d}=.62$; and a medium-sized significant difference between No Function and Replacement Preserves Function, t $(61)=2.52$, p<.05, d=.64.
} 

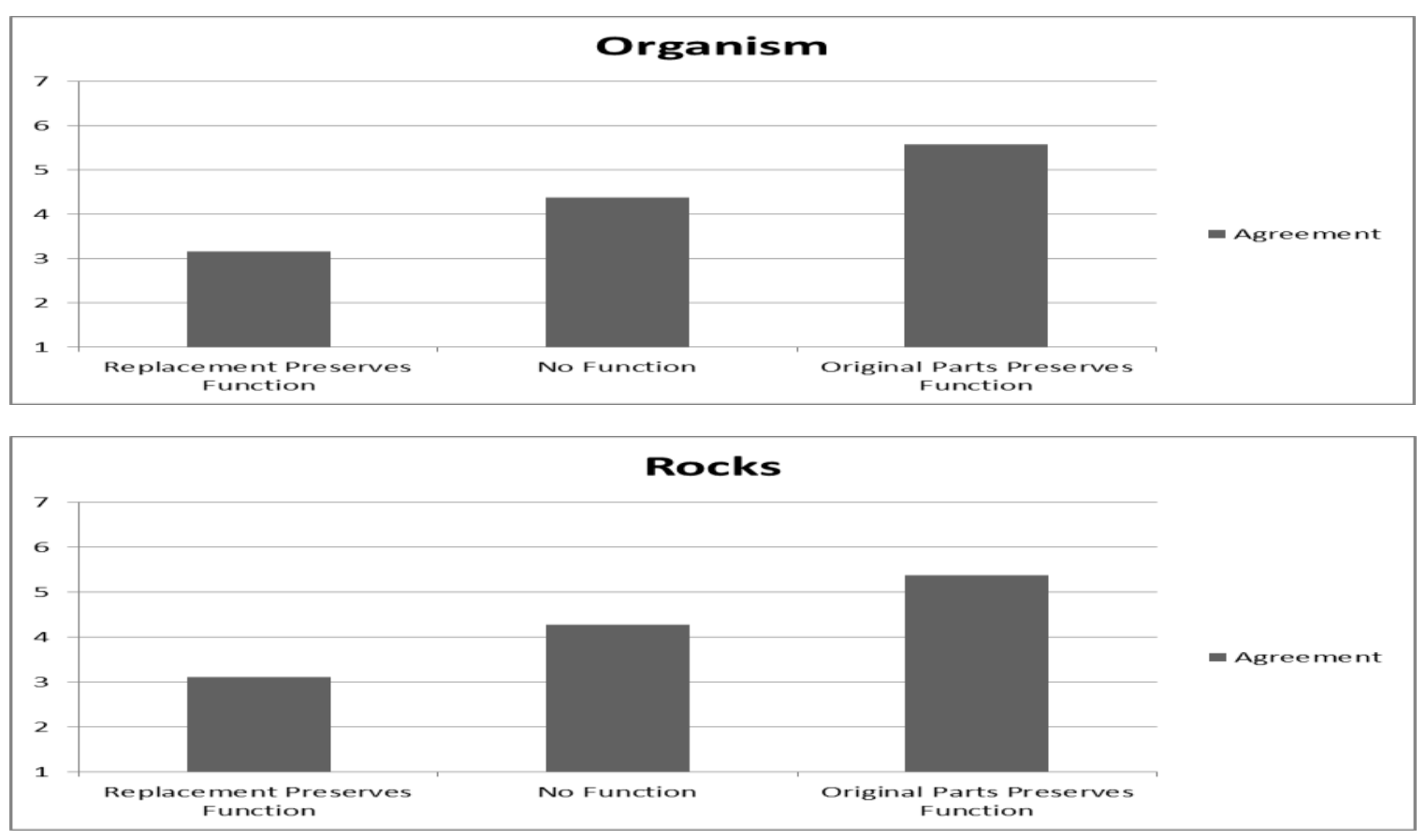

Despite the explicit attempt to remove the "not being a jerk element" (e.g., switching from borrowing to painting a rowboat in the rowboat case, having John say that he does not care what the organism or rock is for in the organism and rock cases), and despite switching the function away from being for a person, participants continued to show the same pattern of teleologically driven intuitions as they did in the first study.

The above result suggest that the folk operate with a teleological view of persistence in that they tend to judge that an object persists when it preserves its function. Though the results from the above cases appear to support the view that the folk operate with a teleological view of persistence, it would be good to find out whether the results are robust and hold up in cases that do not involve gradual part replacement. Furthermore, I suggested that the folk are promiscuous teleologists in that teleological considerations extend to judgments involving non-living natural objects like rocks. But the results in support of this, so far, have only been restricted to cases involving gradual part replacement. To continue to explore the hypothesis that the folk are promiscuous teleologists and that this extends to their general view of how objects persist, I'll focus on cases involving only rocks in what follows.

I'll begin by looking at cases where a rock is smashed into three pieces and either preserves or loses its function.

\subsection{Rock Smashed Into Three Pieces}

I created two cases. In both, John is hiking and finds a rock which is glowing because it hosts special microorganisms. He takes the rock home to study and notices that the rock begins to fade as the microorganisms begin dying. He realizes that the microorganisms feed on minerals in the rock's interior and can't access them. So, he hits the rock with a hammer, breaking it into three pieces so that the microorganisms can access the minerals. In one version, the microorganisms continue to die and it stops glowing while in the other the microorganisms can access the 
minerals and it glows brighter than before. After reading the cases, participants were asked "Has the rock John found survived being hit by the hammer, or has it been destroyed?" and made ratings on a 7 -pt scale anchored with $1=$ It has definitely survived and $7=$ It has definitely been destroyed. 6

The results continued to show a pattern of teleologically driven intuitions, with participants tending to say the rock was destroyed when it lost its function and tending to say that the rock survived when it preserved its function. ${ }^{7}$ Graphically:

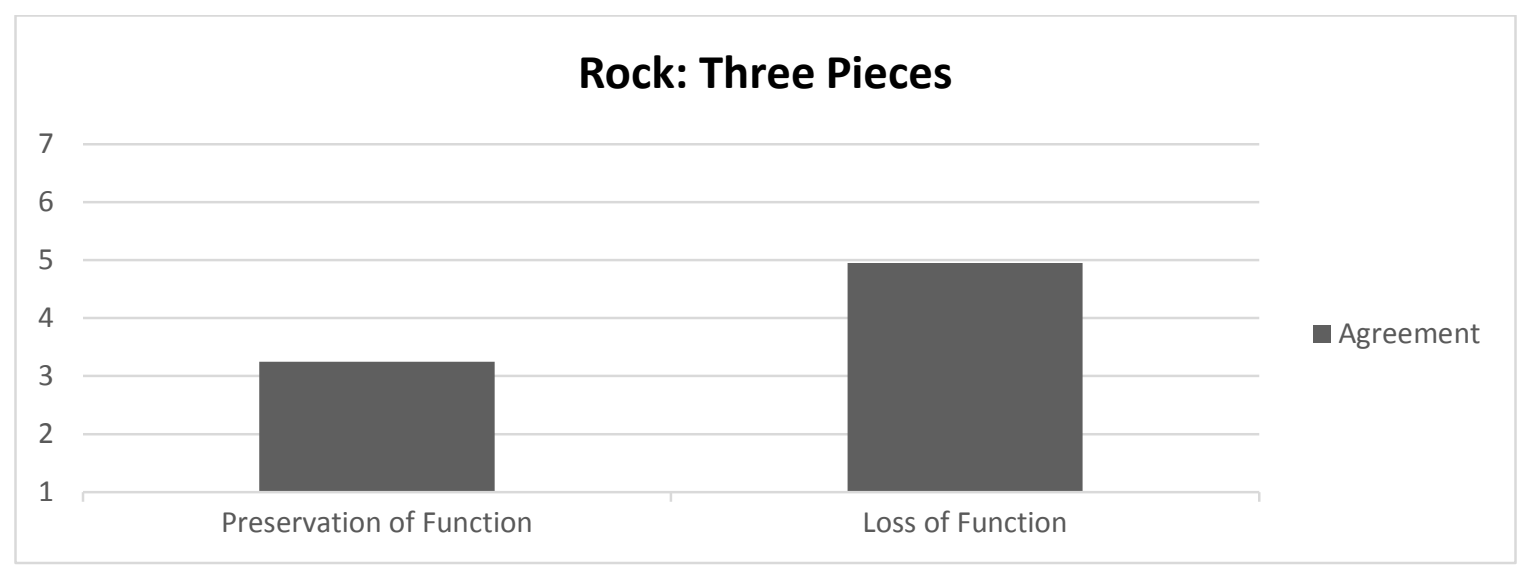

Even when a rock is smashed into three pieces, participants tend to say that it was destroyed when it loses its function and tend to say that it survives when it preserves its function. Thus, even in non-gradual part replacement cases, the results continue to support the hypothesis that folk intuitions about material object persistence are infused with teleological considerations.

Perhaps the effect would not continue to hold up under conditions where the rock undergoes more radical alterations, such as being pulverized. Or perhaps the effect would not continue to show up when the alterations to the rock are only minor, such as being dented. I'll explore both of these in the next study.

\subsection{Denting and Pulverizing}

To explore whether teleological considerations would continue to influence ordinary judgments of persistence, even when the object undergoes only minor alterations, I gave participants a case similar to the one is Section 3.3 where the rock stopped glowing and the microorganisms died after the rock was hit with a hammer. The main difference was that the rock was only dented

\footnotetext{
${ }^{6}$ For full cases, see Appendix.

${ }^{7}$ A total of 95 participants were recruited from Amazon's Mechanical Turk. Participants were randomly assigned to one of two conditions (Function: Lost, Preserved). After reading the case, participants rated the extent to which they thought the rock survived or was destroyed. They were then taken to a separate screen where they were asked two comprehension questions (displayed on separate screens):

(1) John's experiment worked. (Yes/No)

(2) John hit a rock with a hammer and broke it into three pieces. (Yes/No)

7 people were excluded from the data analysis for missing one or more comprehension questions, leaving a total of 88 responses. The results indicated that there was a large-sized effect of whether the rock Lost $(\mathrm{M}=4.93, \mathrm{SD}=1.92)$ or Preserved $(\mathrm{M}=3.27, \mathrm{SD}=1.84)$ its function, $\mathrm{t}(86)=4.13, \mathrm{p}<.001, \mathrm{~d}=.88$.
} 
when hit with the hammer. This was contrasted with a control case where participants were only told that John hit a rock with a hammer and dented it.

And to explore whether teleological considerations would continue to influence ordinary judgments of persistence, even when the object undergoes radical alteration, I gave people a case that was similar to the one in Section 3.3 where the rock continues to glow and the microorganisms survive after the rock is hit with the hammer. The only difference was that participants were told that John smashed the rock when he hit it with the hammer. This case was contrasted with a control case where participants were only told that John smashed a rock with a hammer. In all cases, participants made ratings on the same scale as used in the previous study (Section 3.3). ${ }^{8}$

For the cases which involved the rock being dented, the results indicated that while people tended to agree that the rock survived being dented in the control case, when the rock lost its function as a result of being dented, participants tended to say that the rock had been destroyed. ${ }^{9}$

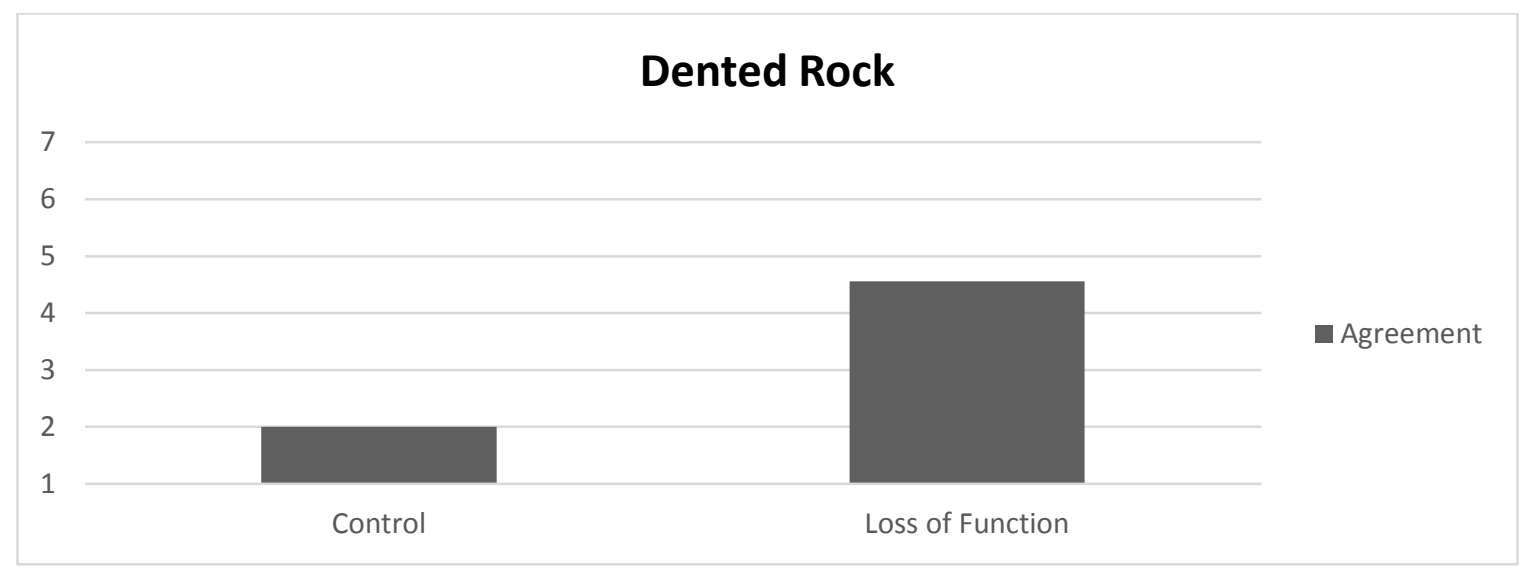

In the pulverized rock version, when the rock was shattered but preserved its function, people tended to agree that the rock survived the smashing in comparison to the control case where participants tended to say that the rock was destroyed. ${ }^{10}$

\footnotetext{
${ }^{8}$ For full cases, see Appendix.

${ }^{9}$ A total of 95 participants were recruited from Amazon's Mechanical Turk. Participants were randomly assigned to one of two conditions (Control, Loss of Function). After reading the case, participants rated the extent to which they thought the rock survived or was destroyed. They were then taken to a separate screen where they were asked two comprehension questions (each displayed on a separate screen):

(1) John's experiment worked. (Yes/No)

(2) John hit a rock with a hammer. (Yes/No)

6 people were excluded from the data analysis for missing one or more comprehension questions, leaving a total of 89 responses. The results indicated that there was a large-sized significant difference between the Control ( $\mathrm{M}=2.06$, $\mathrm{SD}=1.54)$ and Loss of Function Cases $(\mathrm{M}=4.56, \mathrm{SD}=2.10), \mathrm{t}(87)=6.40, \mathrm{p}<.001, \mathrm{~d}=1.36$.

${ }^{10}$ A total of 95 participants were recruited from Amazon's Mechanical Turk. Participants were randomly assigned to one of two conditions (Control, Pulverized). After reading the case, participants rated the extent to which they thought the rock survived or was destroyed. They were then taken to a separate screen where they were asked two comprehension questions (each displayed on a separate screen):
} 


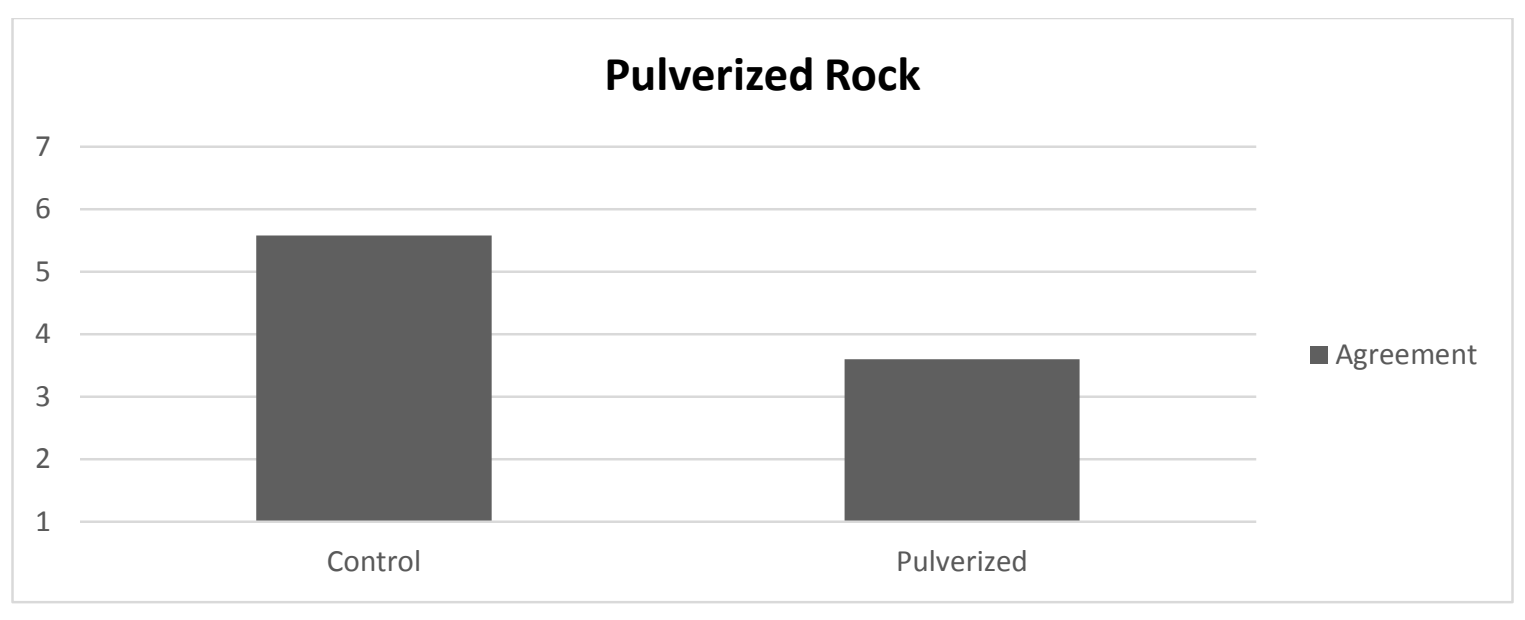

The above results suggest that when a rock undergoes even minor alterations i.e., denting, if it is described as losing its function, people tend to agree that it was destroyed in comparison to a control case. And similarly, in comparison to a control case, when a rock undergoes radical alteration i.e., is pulverized, people tend to say that it survives when it preserves its function.

Perhaps one issue with the previous study is that the extent of the destruction is too ambiguous. Perhaps if pains were taken to make explicit that the rock was radically altered-e.g., smashed to dust-people would be unwilling to say that it survives, despite any preservation of function. Aside from this, the above study used only control cases for comparison and so did not directly manipulate loss/preservation of function in denting or loss/preservation of function in pulverizing. So, this leaves open whether there might be some effect of denting or pulverizing. I'll take all this up in the next and final study.

\subsection{Denting and Pulverizing with Loss and Preservation of Function}

The final set of cases involved John, who discovered a new kind of rock which he named "Zenyte". He noticed tiny worms in the crevices of the rock and gave it to his biologist friend, Frank. Frank notices that the rock transmits chemicals which provide essential nutrients for the worms. The worms begin dying and so he decides to hit the rock with a hammer.

In the denting versions, participants were told that Frank dented the rock with the hammer. They were then either told that the rock did not transmit the unique chemical and the worms continued to die or that the rock began transmitting the chemicals and the worms stopped dying. In the pulverizing versions, participants were told that Frank pounded the rock until it was broke into pieces the size of dust. They were then either told that the rock did not transmit the unique chemical and the worms continued to die or that the rock began transmitting the chemical and the worms stopped dying. ${ }^{11}$

(1) John's experiment worked. (Yes/No)

(2) John hit a rock with a hammer. (Yes/No)

4 people were excluded from the data analysis for missing one or more comprehension questions, leaving a total of 91 responses. The results indicated that there was a large-sized significant difference between the Control $(\mathrm{M}=5.58$, $\mathrm{SD}=1.30)$ and Pulverized Cases $(\mathrm{M}=3.73, \mathrm{SD}=2.24), \mathrm{t}(89)=4.76, \mathrm{p}<.001, \mathrm{~d}=1.01$.

${ }^{11}$ For full cases, see Appendix 
In all cases, participants were told that Frank and John disagreed over whether "Zenyte" was destroyed. Frank says it was not destroyed while John says it was destroyed. In each version of the story, participants were asked to rate the extent to which they agreed with either John or Frank on a 7 -pt scale anchored with $1=$ John is right and $7=$ Frank is right.

The results indicated a strong effect of whether the rock lost or preserved its function. There was no effect of denting or pulverizing and no interaction between denting or pulverizing and loss or preservation of function. ${ }^{12}$ Graphically:

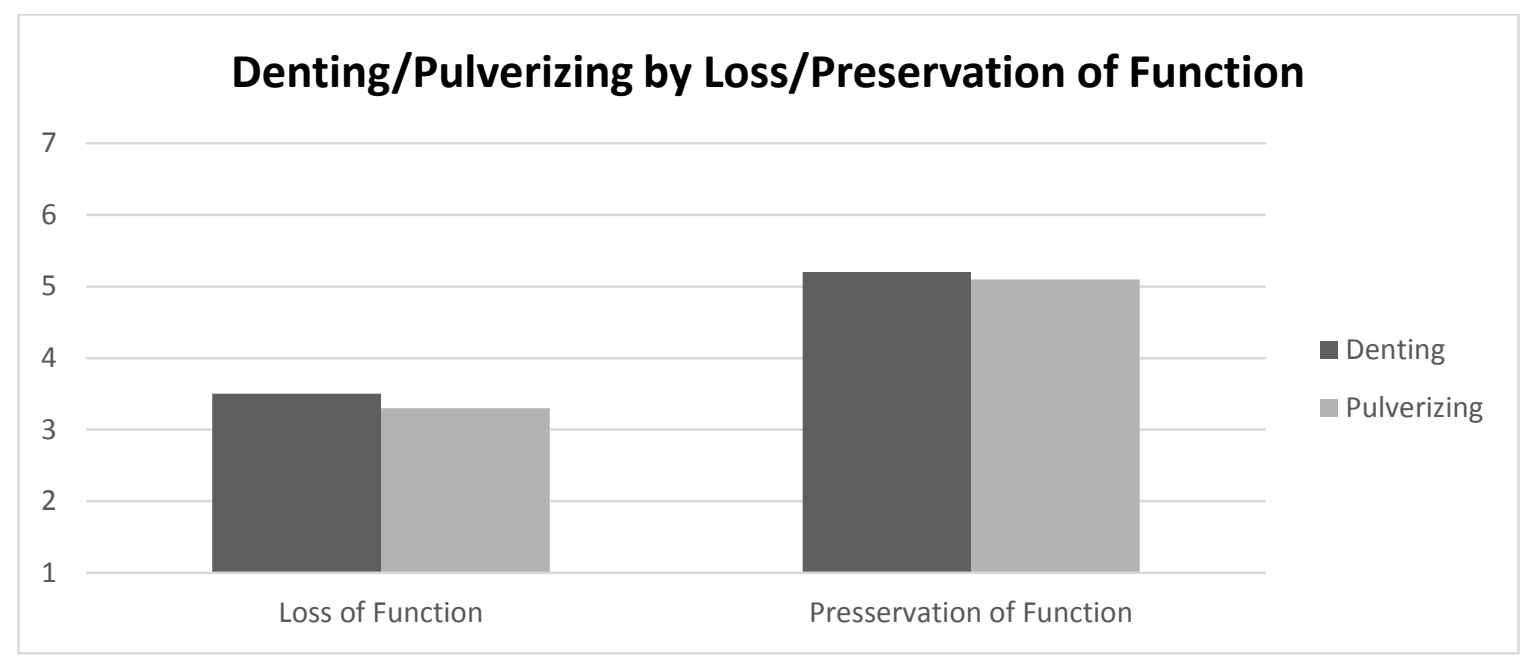

Thus, even when making explicit that the rock has undergone radical alteration - being broken into pieces the size of dust - one continues to see a pattern of teleologically driven intuitions about persistence. Indeed, whether the alteration was radical or minor had no effect whatsoever: only teleological considerations affected ordinary intuitions about material object persistence.

Taken together, the above results indicate that the folk tend to judge that a material object survives alterations when it preserves its function and that a material object is destroyed when it loses its function. And this persists despite whether the alterations are radical or minor. Given the results and the background psychological discussion of promiscuous teleology, I claim empirical support for the hypothesis that the folk operate with a teleological view of material

\footnotetext{
${ }^{12}$ A total of 180 participants were recruited from Amazon's Mechanical Turk. Participants were randomly assigned to one of four conditions in a 2 (Function: Lost, Preserved) x 2 (Damage Type: Denting, Pulverizing) design. After reading the case, participants rated the extent to which they agreed with either John or Frank. They were then taken to a separate screen where they were asked two comprehension questions (each displayed on a separate screen):

(1) John is a geologist. (Yes/No)

(2) Frank broke the rock into tiny pieces. (Yes/No)

12 people were excluded from the data analysis for missing one or more comprehension questions, leaving a total of 168 responses. The results indicated that there was a large-sized effect of Function, $\mathrm{F}(1,164)=40.842, \mathrm{p}<.001$, $\eta p^{2}=.199$; no effect of Damage Type, $\mathrm{F}(1,164)=.467, \mathrm{p}>.05$; and no interaction between Function and Damage Type, $\mathrm{F}(1,164)=.049, \mathrm{p}>.05$. Planned pairwise comparisons revealed a large-sized significant difference between Loss $(M=3.53, S D=2.09)$ and Preservation of Function $(M=5.26, S D=1.73)$ in the Denting Condition, $t(80)=4.03$, $\mathrm{p}<.001, \mathrm{~d}=.91$ and a large-sized significant difference between Loss $(\mathrm{M}=3.28, \mathrm{SD}=1.84)$ and Preservation of Function $(\mathrm{M}=5.13, \mathrm{SD}=1.51)$ in the Pulverizing Condition, $\mathrm{t}(84)=5.09, \mathrm{p}<.001, \mathrm{~d}=1.09$.
} 
object persistence. More specifically, I hold that the folk operate with something like the following implicit view of material object persistence:

Persistence Through Function Preservation: Material objects persist through alterations when their functions are preserved.

It may be objected that the results only support the view that teleology is only one factor in folk judgments about material object persistence. ${ }^{13}$ Perhaps there are additional factors that feature in folk judgments of persistence. I acknowledge that there may be other factors involved in folk judgments of persistence. I would reiterate that my results, as with any empirical work, are defeasible and that I'm open to further work showing that further factors feature in folk judgments of material object persistence. That said, I would only point out that some candidate further factors investigated here - type of object (Sections 3.1 and 3.2) and extent of alterations (Section 3.5)—did not affect folk judgments of persistence. ${ }^{14}$ So, while there may be further factors at play in folk judgments of persistence, I take it that teleological considerations at least play a significant role in folk judgments of persistence. Setting this aside, my goal is to debunk folk intuitions on the grounds that they are rooted in primitive, superstitious thinking (Section 4.2). And for that purpose, whether there are additional factors makes no difference to my ultimate conclusion. Thus, I'll set the issue of whether there are further factors featuring in folk judgments of persistence aside in what follows.

\section{Meeting the Challenge from Folk Belief}

Taken together, the results from Section III suggest that the folk view of material object persistence is teleological in that the folk tend to intuit that an object survives alterations when the object preserves its function and is destroyed when an object loses its function. The folk are not selective teleologists; rather, they are promiscuous teleologists in that teleological considerations infuse judgments about persistence for artifacts, organisms and non-living natural objects (Section 3.1 and 3.2). Furthermore, teleological considerations continue to strongly influence judgments about material object persistence even when alterations to a candidate object are minor or severe (Sections 3.3-3.5).

\footnotetext{
${ }^{13}$ Relatedly, one might wonder whether the above results even support the view that an objects function or purpose affects folk judgments of persistence. Instead, it may be that the preservation or loss of any salient feature or property of an object serves as a criterion in folk judgments of persistence. There is, however, considerable reason to doubt that this is the case given the background psychological literature on the role of teleology in our conception of objects. Nonetheless, I looked at vignettes where the rock changed/preserved owners, just to check that people weren't blindly picking up on whatever the vignette discussed as a criterion for persistence. As expected there was no effect of ownership on persistence judgments (see Appendix).

${ }^{14}$ Connected to this, Rose and Schaffer (2014) found no effect of contact or fusion, of familiarity or labeling or of quantifier restrictions on folk judgments of mereological composition. But they found a large, robust and persistent effect of function or purpose on folk judgments of mereological composition with the folk judging that composition occurred when the plurality had a purpose. Also, after completing this manuscript, Josh Knobe brought to my attention recent work by Nina Strominger and Shaun Nichols (2014) on the persistence of persons as well as a manuscript of his own investigating the role of moral valence in persistence judgments.
} 
Given empirical support for the claim that the folk view of material object persistence is teleological, I now want to consider what, if any, methodological consequences can be drawn. I'll argue that, in the specific case of material object persistence, the folk deserve to be ignored since the folk view is tied into a benighted teleological view of nature. That is, I'll argue that there is a debunking explanation for folk intuitions of material object persistence.

I'll begin by situating the discussion within a background of what Dan Korman (2009) calls the challenge from folk belief (Section 4.1). Having presented this challenge, I then show how it can be met in the specific case of material object persistence. To do so, I'll argue that the teleological view that the folk operate with is an illegitimate, benighted form of teleology (Section 4.2) and that there is a targeted debunking explanation for folk intuition about material object persistence (Section 4.3).

\subsection{The Challenge from Folk Belief}

Metaphysical theories are often judged by their fit with common sense and resultant metaphysical theories are often given more credence when they align more closely with common sense. Indeed, the prescriptive metaphysician who eschews allegiance with common sense accrues an explanatory burden; the prescriptive metaphysician is often charged with the task of explaining just how and where common sense has gone wrong. As Dan Korman (2009) puts it, "[V]irtually everyone agrees that, even after having presented the arguments for their positions, proponents of revisionary philosophical theories - that is, those that deviate from the pretheoretical conception - are required to provide some sort of account of the conflict between their theories and the pretheoretical beliefs of non-philosophers ("the folk")." (p. 242).

For the prescriptive metaphysician, providing a plausible account of the conflict is no simple task. Indeed, Paul (2012) tells us that metaphysical theories which "sacrifice central commonsense tenants only rarely convince" (p. 22); Hirsch (2002) claims that "revisionists standardly delude themselves into thinking that they can plausibly explain why people make the mistakes they allege" (p. 117); and Korman (2009) tells us that "despite all that [revisionists] have said on the topic of folk belief - the "scorecard" of costs and benefits should reflect the fact that they have not met (and probably cannot meet) the challenge from folk belief." (p. 243).

The task for the prescriptive metaphysician then is to meet the challenge from folk belief: the prescriptive metaphysician should explain why the folk believe as they do when the resultant theory apparently conflicts with relevant folk beliefs and do so in a way that is not (1) globally self-defeating or (2) locally self-defeating.

An explanation of the alleged error will be globally self-defeating if the alleged source of error is "so thoroughgoing, [that] the most likely source [of the error] would seem to be... a general inability to form true beliefs about the world" since it would then be "unrealistically optimistic for the eliminativists to put any credence in the belief forming mechanisms or lines of reasoning that led them to accept eliminativism" (p. 244). And an explanation of the alleged source of error will be locally self-defeating "to the extent that it undercuts the justification for some specific claim(s) that one has made" (p. 244). For instance, if one locates the alleged source of error in mistaken intuitions and so embraces a general skepticism about intuitive judgments, then 
one cannot also rely on intuitions to support the premises in an argument for some revisionary or eliminative view. Finally, I would add that, in addition to providing an account that is neither globally nor locally self-defeating, the resulting account must meet a further constraint: (3) the resulting explanation should not be ad hoc. In short, the resulting explanation should cohere well with general and independently established psychological claims.

Despite the pessimism over the prospects of meeting the challenge from folk belief, I think the challenge can be met. In particular, the challenge can be met by providing a targeted debunking explanation of the relevant folk beliefs which is aided and guided by work in cognitive science. In this way, one can provide an account which is neither locally self-defeating, globally selfdefeating, nor ad hoc and thereby meet the challenge from folk belief. In the specific case of material object persistence, I show that the challenge from folk belief can be met. I'll begin by arguing that the folk operate with a benighted teleological view of nature. Having done so, I will argue that there is a targeted debunking explanation for folk intuitions about material object persistence.

\subsection{Benighted Teleology}

It is widely agreed that teleology is a vestige of an outmoded, pre-enlightenment, Aristotelian perspective on the natural world. It is incompatible with the modern scientific image; introduces occult forces; is mentalistic; is incompatible with mechanistic causation; and is empirically untestable (e.g., Mayr, 1998; Allen and Bekoff, 1994). As such, "the inquisition of Final Causes is barren, and like a virgin consecrated to God produces nothing” (Bacon, 1996, pg., 365). So, insofar as the prescriptive metaphysician views herself as allied to the sciences, she ought to reject a teleological perspective on the natural world and, as such, the folk view of material object persistence, since it is encrusted with the muck and funk of a benighted teleological perspective. As Paul (2012) puts it "after drawing on experience to develop a theory, in evaluating it we need to look back at the natural science just in case our ordinary experience of the world conflicts with what our best natural science says about the world. If it does conflict, then often the assumptions based on ordinary experience should be rejected" (p. 17). Given the conflict between the teleological commitments of the folk in the case of material object persistence and the (presumptive) commitments of the prescriptive metaphysician who views herself as allied with the sciences, in the specific case of material object persistence, I hold that the prescriptive metaphysician should ignore the folk.

One might hold, however, that the folk do not operate with a benighted teleological view. Taking cue from disputes among philosophers of biology, the guiding view is that there are scientifically legitimate forms of teleology and there are scientifically illegitimate forms of teleology. An instance of the former would be teleonaturalism, while an instance of the latter would be teleomentalism. Perhaps the metaphysician who bears allegiance to common sense would hold that folk teleology best fits with teleonaturalism and as such is entirely compatible with a scientific perspective. 
Teleomentalists regard "the teleology of psychological intentions, goals, and purposes as the primary model for understanding teleology in biology" (Allen and Bekoff, 1994, p. 13).

Whether teleomentalism is taken literally or metaphorically, it is typically regarded as eliminable (Allen, 2009; Allen and Bekoff, 1994). Those who reject teleomentalism-teleonaturalists"seek naturalistic truth conditions for teleological claims in biology that do not refer to the intentions, goals, or purposes of psychological agents" and so attempt to "reduce teleological language to forms of description and explanation that are found in other parts of science" (Allen and Bekoff, 1994, pp. 13-14). ${ }^{15}$ Given that teleonaturalism is typically taken to be a scientifically legitimate form of teleology, perhaps folk teleology is similarly legitimate.

Though there may be scientifically legitimate teleological notions, folk teleology does not operate with any such notions. Rather folk teleological thinking uses primitive and superstitious notions. Folk teleology best fits the crude superstition of teleomentalism.

A classical demonstration of our adult tendency toward teleomentalism is found in Heider and Simmel (1944), who made a simple movie in which geometrical figures - circles, squares, triangles - moved in certain systematic ways. When shown this movie, people instinctively describe the figures as if they have goals and desires. And more recent research has found that this effect persists even with unbounded figures, such as moving dots and swarms of tiny squares (Bloom \& Veres, 1999).

Indeed, Guthrie (1993) presents a range of experiments showing that people attribute purpose and design to a striking range of real-world entities such as cities, clouds, earthquakes, fire, hurricanes, the moon, mountains, plants, rain, the sun, rivers, rocks, trees, volcanoes, water, and wind. Other work on adult judgments of mental states suggests that adults have a tendency to attribute mental states (e.g., feeling pain, being happy) to plants (Arico et al. 2011).

We have what Pascal Boyer (2001) has called a 'hypertrophy of social cognition': a willingness to attribute purpose, agency and design, even when it is inappropriate to do so. We are "hypersensitive to signs of purpose, design and agency, so much so that we see purpose where all that really exists is artifice or accident" (Bloom, 2007, p. 150). Moreover, as Bloom (2007, p. 150) notes:

We have a bias to attribute an agent when we see nonrandom structure. This is the impetus for the argument for design - the intuition that the design that is apparent in the natural and biological world is evidence for a designer... When we see complex structure, we see it as the product of beliefs and goals and desires. We chew over the natural word with our social mode of understanding, and it is difficult to make sense of it in any other way.

As experts who have overcome the naïve folk theory, it can perhaps seem somewhat surprising that the folk teleology best fits with teleomentalism (see "the curse of knowledge" in Section 4.3). In the biological domain, for instance, it can seem incredible that the folk view of biological functions would be rooted in teleomentalism. But as decades of research in scientific

\footnotetext{
${ }^{15}$ Examples of teleonaturalist accounts can be found in e.g., Millikan (1989) and Cummins (1975).
} 
education suggest, teleological thinking is one of the primary obstacles in students' path to acquiring an adequate understanding of natural selection (see Galli and Meinardi, 2011 and Kelemen, 2012 for an overview). For instance, students tend to think that a "personified "Mother Nature" responded to animals functional needs by generating or conferring the functional part with a view to preserving the animal's survival" (Kelemen, 2012, p. 4; see also Kampourakis \& Zogza, 2008; Moore et al., 2002; and Gregory, 2009), such as by stretching a giraffe's neck so it could reach leaves on trees (e.g., Clough \& Wood-Robinson, 1985;

Demastes, Settlage, \& Good, 1995; Evans et al., 2010; Jensen \& Finley,1995; Kampourakis and Zogza, 2008). Summing up a range of this work, Kelemen (2012) suggests that people's teleological views are "embedded within a framework of intuitions characterizing Nature as a designing agent” (p. 6).

In support of this, Kelemen (2012) reports on work conducted with Rottman and Seston (2013). In this study participants filled out the Conceptual Inventory of Natural Selection (CINS) and were independently asked a range of questions aimed at assessing religious, scientific and quasiscientific beliefs such as "I believe Nature is driven to preserve things". Surprisingly, the results showed that:

[U]ndergraduates' mean level of agreement... with the scientifically unwarranted statement "I believe Nature is driven to preserve living things" was relatively high (59\%) as was their mean agreement with highly correlated statements such as "I believe the Earth is alive" (64\%); "I believe that Nature is a powerful being" (73\%); "The Earth is driven to provide optimal conditions for Life" (62\%). In general then, these students who strongly endorsed natural selection as an explanation of both human $(\mathrm{M}=82 \%)$ and nonhuman origins $(\mathrm{M}=81 \%)$, had a marked tendency to view the Earth as a powerful, protective, controlling being. More importantly, this agentive view of Nature was found to be highly correlated with students' rather high tendency...to endorse inaccurate... answer options on the CINS... (Kelemen, 2012, pgs 6-7)

Summing all this up, Kelemen (2012, p. 7) writes:

Findings suggesting that underlying beliefs about natural agency exert non-obvious influence on students' biological reasoning are potentially less surprising when considered in a broader context of research which suggests that such immanent agentive ideas influence adults' scientifically incorrect ideas about living and non-living nature more generally. For example, in contrast to their ratings of belief in God, students' ratings of the Gaia notion that "Nature is driven to preserve living things" has been found to strongly predict undergraduates promiscuous (but often covert) tendencies to teleologically explain not only living but also non-living natural phenomena in terms of a purpose: That is, an agentive construal of nature provides a significant reason why American undergraduates find scientifically inaccurate teleological statements such as "the sun makes light so that plants can photosynthesize" highly believable even after extensive high school and college level instruction in both the physical and life sciences (Kelemen et al., 2013; also Kelemen \& Rosset, 2009) 
Taken together, the best evidence suggests that telomentalism is the more accurate characterization of folk teleology. This interpretation coheres with a wide swath of research in cognitive science and science education and thus deserves more credence on that basis. That said, one might think that some of the studies I've already presented suggest that the folk view fits with teleonaturalism. For instance, one might think that the rowboat cases (Sections 3.1 and 3.2) are importantly different from the rock cases (Sections 3.3-3.5). Specifically, in the rowboat case a person makes it to serve a certain purpose but in the rock case this does not happen, the rock has a sort of "natural purpose". Perhaps this fits a teleonaturalist construal of folk teleology.

To find out whether a teleonaturalist construal of folk teleology best explains the pattern of results in the rock cases, I decided to rerun one of the rock cases, but with a twist. Participants received Rock Three Pieces Cases (see Section 3.3) and we're randomly assigned to the Loss and Preservation of Function conditions. The same probe and control questions used in Section 3.3 were used here. Importantly, participants were also asked to rate the extent to which they agreed or disagreed, on a 7-pt scale (anchored with $1=$ strongly disagree and $7=$ strongly agree), with the following Gaia Belief probe (taken from Kelemen, Rottman and Seston, 2013):

Gaia Belief Probe: I believe Nature is driven to preserve things.

People's endorsement of quasi-religious Gaia beliefs has been shown to significantly predict endorsement of scientifically illegitimate, teleological explanations for biological and non-living natural phenomenon (Kelemen et al, 2013). Extending this: if Gaia beliefs play a role in people's persistence judgments then we should expect endorsement of Gaia beliefs to predict persistence judgments. Such a finding would support the role of teleomentalism in persistence judgments. Alternatively, if Gaia beliefs play no role in predicting persistence judgments, then this would provide some evidence that teleomentalism does not play a role in persistence judgments.

First, the pattern of results reported in Section 3.3 was replicated, with participants tending to agree that the rock was destroyed when it lost its function $(M=5.60, S D=1.54)$ after being smashed into three pieces and tending to agree that it survived when it preserved its function $(\mathrm{M}=3.45, \mathrm{SD}=2.05)$ after being smashed into three pieces, $\mathrm{F}(1,99)=34.130, \mathrm{p}<.001 .{ }^{16}$ Second, a multiple regression model, with both Condition and Gaia Belief ${ }^{17}$ as predictors of persistence judgments revealed that both factors significantly predicted persistence judgments. ${ }^{18}$

\footnotetext{
${ }^{16}$ A total of 110 participants were recruited from Amazon's Mechanical Turk. Participants were randomly assigned to one of two conditions (Function: Lost, Preserved). After reading the case, participants rated the extent to which they thought the rock survived or was destroyed. After this they answered the same two comprehension question used above in Section 3.3 and were given the Gaia Belief Probe. The presentation of each of the items-the two comprehension questions and Gaia Belief Probe-was randomized. 10 people were excluded from the data analysis for missing one or more comprehension questions, leaving a total of 100 responses.

${ }^{17}$ Overall, Gaia belief endorsement was fairly high, $\mathrm{M}=4.8, \mathrm{SD}=1.96$. The median was 5 and the mode was 7.

${ }^{18}$ Both Condition and Gaia Belief had a large-sized effect on persistence judgments, $\mathrm{R}^{2}=.317 . \mathrm{R}^{2}$ indicates the amount of variance in the dependent variable explained by the linear model. Following Ellis (2010), values greater than or equal to .26 are large, greater than or equal to .13 but less than .26 are medium, and values greater than or equal to .02 but less than .13 are small.
} 


\begin{tabular}{|c|c|c|c|}
\hline Variable & Beta & t-value & p-value \\
\hline Condition & -.522 & -6.207 & .001 \\
\hline Gaia Belief & -.242 & -2.883 & .005 \\
\hline
\end{tabular}

To get a clearer picture of the relationships among these factors, I ran a causal search over the data using Greedy Equivalence Search (GES). ${ }^{19}$ The model returned: ${ }^{20}$

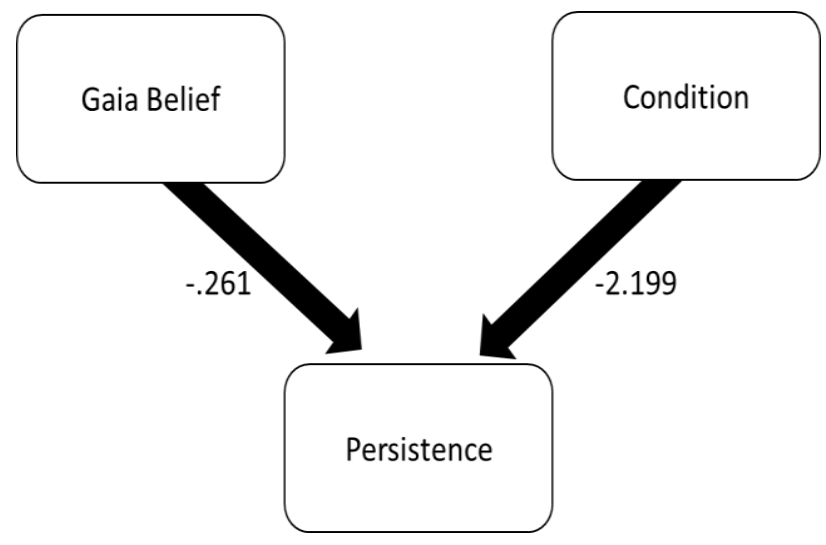

This model shows that persistence is a collider: ${ }^{21}$ both variables-Gaia Belief and Conditionindependently cause persistence judgments. This makes perfect sense. For instance, we would not expect Condition (i.e., whether the rock preserves or loses its function) to cause Gaia Beliefs. Rather, we would expect the quasi-religious Gaia Belief to be held independent of any information about whether an actual object loses or preserves its function. In other words, we would not expect Gaia Beliefs to mediate the effect of Condition on persistence judgments. ${ }^{22}$ We would, however, expect that if Gaia Beliefs are playing a role in persistence judgments, that they would play a direct causal role in persistence judgments. And indeed, this is just what was found: Gaia Beliefs play a direct causal role in people's function-based persistence judgments. Given that Gaia Beliefs did not fail to predict persistence judgments, a teleonaturalist construal of the folk understanding of teleology seems untenable. The evidence suggests that the proper construal of folk teleology is in terms of teleomentalism.

\footnotetext{
${ }^{19}$ Roughly, GES operates by considering the possible models available given the different variables. GES begins by assigning an information score to the null model (i.e., a disconnected graph). GES then considers various possible arrows ("edges") between the different variables. It begins by adding the edge that yields the greatest improvement in the information score (if there is such an edge) and repeats the process until additional edges would not further improve the information score. GES then considers deletions which would yield the greatest improvement in the information score (if there is such an edge), repeating this procedure until no further deletions will improve the score. In all cases, the orientation of the edges is given by edge- orientation rules in Meek (1997). It has been shown by Chickering (2002) that, given enough data, GES will return the true causal model of the data. GES is often interpreted as returning the best fitting causal model, given the data. (For further details and some applications, see Chickering, 2002; Rose et al., 2011; Rose and Nichols, 2013; Rose and Nichols, forthcoming.)

${ }^{20}$ This model is a good fit of the data, $\chi^{2}(1)=.3083, \mathrm{p}=.5815, \mathrm{BIC}=-4.3013$

${ }^{21}$ For more, see Alicke, Rose and Bloom, 2011

${ }^{22}$ Put differently: we would not expect changes in whether an actual object preserves or loses its function to cause differences in the extent to which somebody endorsed the Gaia Belief.
} 
Given the current result and its coherence with a wide swath of independent psychological results suggesting that folk teleology best fits teleomentalism, I hold that the overall pattern of teleologically driven intuitions observed in cases of material object persistence best fits teleomentalism. As such, the folk operate with a benighted view of teleology. Folk teleology is thus unfit for real metaphysics.

\subsection{Targeted debunking}

Concerning the folk view of material object persistence, I hold that the folk suffer from an undermining defeater (e.g., Pollock, 1987). Just as the force of testimony is undermined if it is discovered that the testimony is based on a lunatic view on the topic, so too the force of intuition is undermined if it is discovered that the intuitions are based on a hopeless theory of the topic. As such, I hold that there is a debunking explanation for folk intuitions about material object persistence. $^{23}$

Work in folk biology suggests that we tend to judge that something is alive when it exhibits motion. Piaget (1929/1960) famously uncovered an interesting tendency among preschool aged children to attribute life to bicycles, cats, clouds, the sun, snails and water and a tendency to deny that plants are alive. The reason for attributing life to some artifacts, organisms and non-living natural objects but denying that plants are alive is because these varied objects tend to exhibit motion while plants do not (e.g., Richards and Seigler, 1986). And though adults do not tend to judge whether something is alive on the basis of whether it exhibits motion, recent work suggests that these childhood tendencies are never fully outgrown but rather are masked into adulthood. Work by Goldberg and Thompson-Schill (2009)_ placing adults in speeded up conditions to prevent their background beliefs from intruding - found that college aged students and even biology professors tended to classify something (rivers, cars, etc) as alive when it displayed motion and deny that it was alive when it failed to display motion (e.g., plants). They conclude that these "biases within biological knowledge appear to reflect developmental "roots" that cannot be completely overwritten, or replaced, with the acquisition of more advanced knowledge" (p. 435).

Assuming that intuitions about whether something is alive could be shown to trace from the conceptual connection between life and motion, our intuitions about whether something is alive would be debunked and so should be accorded no weight in disputes about biological classification. Likewise if it is discovered that we intuit that material objects survive through alterations when their functions are preserved and are destroyed when their functions are destroyed, intuitions about material object persistence would equally be debunked and should be accorded no weight in disputes about material object persistence.

Given that the folk view of material object persistence is teleological, I claim that there is a debunking explanation for folk intuitions about material object persistence. But, in offering a

\footnotetext{
${ }^{23}$ I follow Kahane (2011) in associating undermining defeaters and debunking explanations: "Debunking arguments are arguments that show the causal origins of a belief to be an undermining defeater." (p. 106). For a connected strategy for debunking — via process debunking — see e.g., Nichols, 2014; Rose, 2014; and Rose and Nichols, forthcoming.
} 
debunking explanation for folk intuitions about material object persistence, one must provide an account which is neither globally nor locally self-defeating (Section 4.1). Thus, one must show that the view of the prescriptive metaphysician is not likewise infused with teleological considerations.

Research suggests that formal scientific training plays some role in conferring the benefit of overcoming the naïve teleological perspective on the world (Casler and Kelemen, 2008). But, other factors may also play a role. In a study by Kelemen, Rottman and Seston (2013) a range of interesting findings emerged. Participants were current college students, non-student laypersons from the community, professional physical scientists and professionals in various humanities departments. ${ }^{24}$ All participants were given various statements that were either scientifically legitimate (e.g., conception occurs because sperm and egg fuse together) or scientifically, illegitimate teleological statements (e.g., the sun radiates heat because warmth nurtures life). Participants were randomly assigned to one of two conditions: a speeded and an unspeeded condition. The purpose of this was to see whether limitations on cognitive resources affected participants' willingness to accept the scientifically illegitimate teleological statements. It turns out that it did: regardless of one's background, participants were more willing to accept teleological statements in speeded conditions. Interestingly, college students (Speeded $=56 \%$, Unspeeded $=45 \%$ ) and non-student laypersons (Speeded $=53 \%$, Unspeeded $=40 \%$ ) displayed a strong overall tendency to endorse teleological statements. In contrast, professionals in the sciences $($ Speeded $=29 \%$, Unspeeded $=15 \%)$ and humanities $($ Speeded $=32 \%$, Unspeeded $=21 \%)$ displayed a much weaker overall tendency to endorse teleological statements. Thus, college students and non-student laypersons, showed a strong, overall tendency toward teleological explanations, regardless of whether they were making more reflective judgments or not. In contrast, professionals in the sciences and humanities, though having a stronger tendency to endorse teleological explanations when their cognitive resources were limited, showed only a slight tendency to endorse teleological explanations when making more reflective judgments. So, the reflective judgments of the experts appear to substantially abate - to the point of near extinction - the tendency toward teleological explanation. ${ }^{25}$

Moreover, Kelemen et al. found that endorsement of the quasi-religious Gaia belief that "Nature is driven to preserve things" did not differ between professionals in the sciences $(\mathrm{M}=2.2)$ and humanities $(\mathrm{M}=2.5){ }^{26}$ And while college students $(\mathrm{M}=3.7)$ and non-student laypersons $(\mathrm{M}=3.9)$ did not differ in the extent to which they endorsed the Gaia belief, college students and nonstudent laypersons showed a much stronger, overall tendency to endorse the Gaia belief in

\footnotetext{
${ }^{24}$ Scientists were from chemistry, physics and geoscience departments and had held a PhD for an average of eight years. Humanities professionals were drawn from classics, English and history departments and had held a PhD for an average of seven years. Professionals from the sciences and humanities were drawn from Columbia, Boston University, Brown, Harvard, Yale and MIT.

${ }^{25}$ Indeed, one might take low frequency of teleological endorsement among professionals in the unspeeded conditions to reflect mere noise. Though it's not entirely clear what the threshold for mere noise is, one reasonable standard is to treat frequencies significantly below or non-significantly different from $20 \%$ to reflect mere noise (see e.g., Murray, Sytsma and Livengood, 2013). If this is right, then the tendency among the professionals to endorse teleological explanations on the basis of reflective judgments might be treated as reflecting nothing more than mere noise. But notice the same could not be said about their unreflective judgments.

${ }^{26}$ Ratings were made of a 5-pt scale with $1=$ strongly disagree and 5=strongly agree
} 
comparison to professionals in the sciences and humanities. So, overall professionals in the sciences and humanities showed both a substantially weaker tendency to endorse teleological explanations and the quasi-religious Gaia belief that "Nature is driven to preserve things".

But what accounts for this decreased tendency to endorse both teleological explanations and the quasi-religious Gaia belief among professional scientists and professionals in the humanities? A natural hypothesis is that professionals in the sciences and humanities have significantly more background scientific knowledge. As it turned out, however, Kelemen et. al. found significant differences between these groups in background scientific knowledge. Though professional scientists displayed significantly more background knowledge - as measured by the Conceptual Inventory of Natural Selection and the Geoscience Concept Inventory-professionals in the humanities did poorly. Indeed, professionals in the humanities displayed no more scientific knowledge than college students or non-student laypersons. Though it seems that formal scientific training may make some difference in the move away from teleological explanations and Gaia beliefs, another factor which may be quite important is the development of more sophisticated conceptual, analytical skills which comes along with extended educational training and experience. And so perhaps this accounts for both the overall decreased tendency among professionals in the sciences and humanities to endorse teleological explanations and Gaia beliefs.

Taken together, these results seem to fit the pattern we would expect if philosophers are indeed experts. Indeed, those who endorse the expertise defense often charge that the intuitions of the folk cannot be trusted since they cannot be relied on to understand the relevant concepts, draw salient distinctions and so forth. Only the intuitions of the philosopher, with her extensive experience in analyzing concepts, drawing salient distinctions and so forth, should be trusted (see e.g., Ludwig, 2007; Rose and Schaffer, 2014; Williamson, 2011). Given that professionals in the sciences and humanities in the Kelemen et al studies were not inclined to reflectively endorse scientifically illegitimate teleological explanations it seems that, in the case of persistence, we should expect philosophers to tend not to reflectively endorse teleological explanations of material object persistence. And, indeed, this is exactly what we see: metaphysicians do not themselves offer teleological views of material object persistence. Only the folk, who are caught up in the muck and funk of teleology, display strong teleological tendencies in determining whether an object that undergoes alterations persists.

But, even though expertise confers the benefit of overcoming naïve folk theory, it also comes at the cost of losing track of how the folk think. While the folk might be cursed with a benighted teleological view of nature, the experts are saddled with the curse of knowledge (Camerer, Loewenstein and Weber, 1989): expertise in a given domain biases the experts to project their own sophisticated views onto the folk and so comes with the cost of losing track of how the folk think (Hinds, 1999). Indeed, in the case of material object persistence, it seems that we see the mark of expertise: metaphysicians do not offer teleological views of material object persistence in their explicit theorizing and they also seem to be blinded to the prospects that the folk view of material object persistence is teleological. So, insofar as the metaphysician enjoys in expertiseand so has overcome the naïve folk theory_-it seems that a targeted debunking explanation for 
folk intuitions about material object persistence is on offer: the folk, given their lack of expertise, operate with a benighted teleological view of material object persistence while the metaphysician, in virtue of her expertise, has overcome the naïve folk theory and so enjoys in a more enlightened perspective. Thus, I clam that there is a targeted debunking explanation for folk intuitions about material object persistence.

In meeting the challenge from folk belief, three conditions need to be met. The account must not be (1) globally self-defeating, (2) locally self-defeating or (3) ad hoc. Thus, to meet the challenge from folk belief one must offer a targeted debunking explanation, aided by cognitive science. ${ }^{27}$ First, I provided empirical evidence of what the folk view is, finding that it is teleological. Second, I situated folk teleology within the psychological background of promiscuous teleology, drawing on the best current empirical evidence which suggests that teleomentalism is the best characterization of folk teleology. I then argued that the views of the metaphysician are not likewise teleologically infused by drawing on empirical work and invoking an expertise defense in the specific case of material object persistence. Thus (1) and (2) are met since the metaphysicians display the marks of expertise and so their reflective judgments appear to issue from an enlightened perspective. And (3) is met since the account, taken together, coheres well with independent psychological claims. The targeted debunking explanation goes through; the challenge from folk belief is met. Taken together, there is a case specific reason for holding that the folk view of material object persistence does not deserve to be taken seriously in disputes over material object persistence. ${ }^{28}$ On this matter, the folk deserve to be ignored.

\section{Conclusion}

Metaphysicians have wanted a view of material object persistence that fits with common sense. Yet there is disagreement over what the folk view of persistence is and no empirical discipline to the dispute. I suggested that, in measuring metaphysical theories against their fit with common sense, empirically discerning what the folk view is can help in deciding whether it deserves to be taken seriously. My hypothesis was that the folk view of material object persistence is teleological. I motivated this by situating it within a background discussion of promiscuous teleology (Section II). Given that we tend to determine whether something is by determining whether there is something it is for, I suggested that this basic pattern would extend to the folk view of material object persistence: whether something persists is given by whether it continues to serve its function. And, in a range of studies (Section III), I provided support for the hypothesis that the folk view of material object persistence is teleological.

I then went on, in Section IV, to draw out the methodological consequences by situating the discussion within a background of the challenge from folk belief. I then argued for a targeted debunking explanation of folk intuitions of material object persistence by arguing that the folk

\footnotetext{
${ }^{27}$ Here I join Goldman (2007) and Paul (2010) in thinking that cognitive science can be useful to metaphysics.

${ }^{28}$ In offering a targeted debunking explanation via an expertise defense for material object persistence, I am endorsing what Rose and Schaffer (2014) call the nuanced view: "the prospects for the expertise defense must be evaluated on a case-by-case basis, in empirically disciplined ways" (p. 32; also see Rose and Danks, 2013)
} 
view is tied into a benighted view of nature (teleomentalism) and by offering an expertise defense in the specific case of persistence.

Taken together, I hold that discussion over material object persistence should be liberated from any demanded conformity with folk intuitions: the prescriptive metaphysician should not be compelled to square her account with the verdicts of the folk. Thus, in the dispute over material object persistence, the folk view should not be taken seriously; there is a case specific reason for holding that metaphysical theories of persistence should not be measured against their fit with common sense.

In liberating the prescriptive metaphysician from any demanded conformity with folk intuitions, one might wonder what metaphysicians can appeal to in deciding between competing theories of material object persistence. ${ }^{29}$ Given that expert metaphysicians disagree over material object persistence and given that the folk operate with a benighted teleological view of material object persistence and, as such, should be ignored in the dispute over material object persistence, what's left? Perhaps appealing to consistency or coherence might help in deciding between competing metaphysical theories of material object persistence. But it appears that some competing metaphysical theories of material object persistence - for instance, three dimensionalism, four dimensionalism and the standard sortal based account - are neither internally inconsistent nor internally incoherent. Perhaps there are still virtues of simplicity, elegance and coherence with wider theory that may help favor certain approaches. Overall, I suspect that liberating metaphysical theories of material object persistence from conformity with folk intuitions tilts the scales in favor of the more elegant four dimensionalist approach. But this is obviously a matter which falls beyond the scope of the current discussion. I'm only defending a descriptive claim about when the folk think that material object persistence occurs and drawing out its methodological implications. I am not defending any claim about when material objects, in fact, persist, nor am I defending any metametaphysical claim about the prospects for metaphysical knowledge. ${ }^{30}$

\section{References}

Alicke, M., Rose, D., \& Bloom, D. (2011). Causation, Norm Violations and Culpable Control. Journal of Philosophy, 108, 670-696.

Allen, C. (2009). Teleological Notions in Biology. The Stanford Encyclopedia of Philosophy, <http://plato.stanford.edu/archives/win2009/entries/teleology-biology/>.

Allen, C \& Bekoff, M. (1994). Function, Natural Design and Animal Behavior: Philosophical and Ethnological Considerations. In N.S. Thompson (ed.), Perspectives in Ethology, Vol. 11: Behavioral Design: pp. 1-47. Plenum Press.

\footnotetext{
${ }^{29}$ I would like to thank an anonymous referee for raising this issue.

${ }^{30}$ I would like to thank David Danks, Josh Knobe, Shaun Nichols, Laurie Paul, Jonathan Schaffer, Stephen Stich, John Turri and an anonymous referee for helpful comments on earlier versions of this paper.
} 
Arico, A., Fiala, B., Goldberg, R., and Nichols, S. (2011). The Folk Psychology of Consciousness. Mind \& Language, 26, 327-352.

Atran, S. (1998). Folk Biology and the Anthropology of Science: Cognitive Universals and Cultural Particulars. Behavioral and Brain Sciences, 21, 547-609.

Bacon, F. (1996). Collected Works of Francis Bacon, vol. 4: Translations of the Philosophical Works, eds. James Spedding, Robert Leslie Ellis, and Douglas Denon Heath. Routledge/Thoemmes Press.

Benovsky, J. (2006). Persistence through Time, and Across Possible Worlds. Ontos Verlag.

Bloom, P. (1996). Intention, History, and Artifact Concepts. Cognition, 60, 1-29.

Bloom, P. (2007). Religion is Natural. Developmental Science, 10, 147-151

Bloom, P., \& Veres, C. (1999). The Perceived Intentionality of Groups. Cognition, 71, B1-B9

Boyer, P. (2001). Religion Explained. New York: Basic Books.

Burke, M. (1994). Preserving the Principle of One Object to a Place: A Novel Account of the Relations among Objects, Sorts, Sortals and Persistence Conditions. Philosophy and Phenomenological Research, 54, 591-624.

Burke, M (1997). Coinciding Objects: Reply to Lowe and Denkel. Analysis, 57, 11-18

Camerer, C., Loewenstein, G. \& Weber, M. (1989). The Curse of Knowledge in Economic Settings: An Experimental Analysis. Journal of Political Economy, 97, 1232-1254.

Casler, K., \& Kelemen, D. (2008). Developmental Continuity in Teleo-Functional Explanation: Reasoning about Nature among Romanian Romani Adults. Journal of Cognition and Development, 9, 340-362.

Chickering, D. (2002). Optimal Structure Identification with Greedy Search. Journal of Machine Learning Research, 3, 507-554.

Clough, E. E. \& Wood-Robinson, C. (1985). How Secondary Students Interpret Instances of Biological Adaptation. Journal of Biological Education, 19, 125-30.

Cummins, R. (1975). Functional Analysis. Journal of Philosophy, 72, 741.765.

De Freitas, J., Tobia, K., Newman, G., Knobe, J. (manuscript). The Good Ship Theseus: The Effect of Valence on Object Identity Judgments.

Demastes, S., Settlage, J., \& Good, R. (1995). Students' Conceptions of Natural Selection and its Role in Evolution: Cases of Replication and Comparison. Journal of Research in Science Teaching, 32, 535-550.

Ellis, P. (2010). The Essential Guide to Effect Sizes: Statistical Power, Meta-Analysis and the Interpretation of Research Results. Cambridge University Press. 
Evans, E. M., Spiegel, A.N., Gram, W., Frazier, B.N., Tare, M., Thompson, S., \& Diamond, J. (2010). A Conceptual Guide to Natural History Museum Visitors Understanding of Evolution. Journal of Research in Science Teaching, 47, 326-353.

German, T. \& Johnson, S. (2002). Functions and the Origin of the Design Stance. Journal of Cognition and Development, 3, 279-300

Goldberg, R. \& Thompson-Schill, S. (2009). Developmental "Roots" in Mature Biological Knowledge. Psychological Science, 20, 480-487.

Goldman, A. (2007). A Program for "Naturalizing" Metaphysics, with Application to the Ontology of Events. The Monist, 90, 457-479

Gonzales Galli, L., \& Meinardi, E. (2011). The Role of Teleological Thinking in Learning the Darwinian Model of Evolution. Evolution Education Outreach, 4, 145-152.

Gregory, T. R. (2009). Understanding Natural Selection: Essential Concepts and Common misconceptions. Evolution: Education and Outreach, 2, 156-175.

Guthrie, S.E. (1993). Faces in the Clouds: A New Theory of Religion. New York: Oxford University Press.

Hawley, K. (2001). How Things Persist. Oxford University Press.

Hawthorne, J. (2008). Three Dimensionalism vs Four Dimensionalism. In Sider, T., Hawthorne, J. \& Zimmerman, D. (Eds.), Contemporary Debates in Metaphysics: Blackwell.

Heider, F., \& Simmel, M. (1944). An Experimental Study of Apparent Behavior. American Journal of Psychology, 57, 243-259.

Hinds, P. (1999). The Curse of Expertise: The Effects of Expertise and Debiasing Methods on Predictions of Novice Performance. Journal of Experimental Psychology: Applied, 5, 202-221.

Hirsch, E. (1982). The Concept of Identity. Oxford: Oxford University Press

Hirsch, E. (2002), Against Revisionary Ontology. Philosophical Topics, 30, 103-127.

Jensen, M. S. \& Finley, F. N. (1995). Teaching Evolution Using Historical Arguments in a Conceptual Change Strategy. Science Education, 79, 147-166.

Kahane, G. (2011). Evolutionary Debunking Arguments. Nous, 45, 103-125.

Kampourakis, K. \& Zogza, V. (2008). Students' Intuitive Explanations of the Causes of Homologies and Adaptations. Science and Education, 17, 27-47.

Keil, F. (1995). The Growth of Causal Understandings of Natural Kinds. Causal Cognition: A Multidisciplinary Debate. (Eds.). Sperber, D., Premack, D \& Premack, A. J. pp. 234-262. Oxford University Press 
Kelemen, D. (1999a). The Scope of Teleological Thinking in Preschool Children. Cognition, 70, 241-272.

Kelemen, D. (1999b). Why are Rocks Pointy? Children's Preference for Teleological Explanations of the Natural World. Developmental Psychology, 35, 1440-1452.

Kelemen, D. (2004). Are Children "Intuitive Theists"? Reasoning about Purpose and Design in Nature. Psychological Science, 15, 295-301.

Kelemen, D. (2012). Teleological Minds: How Natural Intuitions About Agency and Purpose Influence Learning About Evolution. In K. S. Rosengren, S. K. Brem, E. M. Evans \& G. M. Sinatra (Eds.), Evolution challenges: Integrating research and practice in teaching and learning about evolution. Oxford: Oxford University Press.

Kelemen, D. \& DiYanni, C. (2005). Intuitions about Origins: Purpose and Intelligent Design in Children's Reasoning about Nature. Journal of Cognition and Development, 6, 3-31.

Kelemen, D., \& Rosset, E. (2009). The Human Function Compunction: Teleological Explanation in Adults. Cognition, 111, 138-143.

Kelemen, D., Rottman, J. \& Seston, R. (2013). Professional Physical Scientists Display Tenacious Teleological Tendencies: Purpose-Based Reasoning as a Cognitive Default. Journal of Experimental Psychology: General, 142, 1074-1083.

Korman, D. (2009). Eliminativism and the Challenge from Folk Belief. Noûs, 43, 242-264.

Lewis, D. (1986). On the Plurality of Worlds. Oxford: Basil Blackwell

Lombrozo, T., Kelemen, D., \& Zaitchik, D. (2007). Inferring Design: Evidence for a Preference for Teleological Explanation in Patients with Alzheimer's Disease. Psychological Science, 18, 999-1006

Lowe, E. J. (1995). Coinciding Objects: In Defense of the 'Standard Account'. Analysis, 55, 171-178

Ludwig, K. (2007). The Epistemology of Thought Experiments: First Person Versus Third Person Approaches. Midwest Studies in Philosophy, 31, 128-159

Mayr, E. (1998). The Multiple Meanings of Teleological. History and Philosophy of the Life Sciences, 20, 35-40.

Meek, C. (1997). Graphical Models: Selecting Causal and Statistical Models. PhD Thesis, Carnegie Mellon University.

Merricks, T. (1994). Endurance and Indiscernibility. Journal of Philosophy, 91, 165-184.

Millikan, R. G. (1989). In Defense of Proper Functions. Philosophy of Science, 56, 288-302. 
Moore, R., Mitchell, G., Bally, R., Inglis, M., Day, J., \& Jacobs, D. (2002). Undergraduates Understanding of Evolution: Ascription of Agency as a Problem for Student Learning. Journal of Biological Education, 36, 65-71.

Murray, D., Sytsma, J. \& Livengood, J. (2013). God Knows (But Does God Believe). Philosophical Studies, 166, 83-107.

Nichols, S. (2014). Process Debunking and Ethics. Ethics, 124, 727-749.

Paul, L. A. (2002). Logical Parts. Nous, 36, 578-596.

Paul, L. A. (2010). A New Role for Experimental Work in Metaphysics. Review of Philosophy and Psychology, 1, 461-476.

Paul, L. A. (2012). Metaphysics as Modeling: The Handmaiden's Tale. Philosophical Studies, $160,1-29$

Parsons, J. (2000). Must a Four Dimensionalist Believe in Temporal Parts? The Monist, 83, $399-418$.

Piaget, J. (1960). The Child's Conception of the World (J. Tomlinson \& A. Tomlinson, Trans.). Paterson, NJ: Littlefield, Adams \& Co. (Original work published 1929)

Pollock, J. (1987). Defeasible Reasoning. Cognitive Science, 11, 481-518

Richards, D.D., \& Siegler, R.S. (1986). Children's Understanding of the Attributes of Life. Journal of Experimental Child Psychology, 42, 1-22

Rose, D. (2014). Folk Intuitions of Actual Causation: A Two-Pronged Debunking Explanation. Unpublished Manuscript. Rutgers University.

Rose, D. \& Danks, D. (2013). In Defense of a Broad Conception of Experimental Philosophy. Metaphilosophy, 44, 512-534.

Rose, D., Livengood, J., Sytsma, J., \& Machery, E. (2011). Deep Trouble for the Deep Self. Philosophical Psychology, 25, 629-646.

Rose, D., \& Nichols, S. (2013). The Lesson of Bypassing. Review of Philosophy and Psychology, 4, 599-619.

Rose, D. \& Nichols, S. (forthcoming). From Punishment to Moral Objectivity. In Cuneo, T \& Loeb, D (Eds.), The Empirical Dimensions of Metaethics. Oxford University Press.

Rose, D., \& Schaffer, J. (2014). Folk Mereology is Teleological. Unpublished Manuscript, Rutgers University.

Sidelle, A. (2002). Is There a True Metaphysics of Material Objects? Philosophical Issues, 12, 118-145.

Sider, T. (2001). Four Dimensionalism. Oxford University Press 
Strominger, N. \& Nichols, S. (2014). The Essential Moral Self. Cognition, 131, 159-171.

Thomson, J. (1983). Parthood and Identity Across Time. Journal of Philosophy, 80, 201-220.

Van Inwagen, P. (1990). Material Beings. Ithaca: Cornell.

Wiggins, D. (1968). On Being in the Same Place at the Same Time. Philosophical Review, 77, 90-95

Wiggins, D. (1980). Sameness and Substance. Cambridge: Harvard University Press

Williamson, T. (2011). Philosophical Expertise and the Burden of Proof. Metaphilosophy, 42, 215-229 


\section{Appendix}

\section{Study 1 (Section 3.1: Rowboat, Organism and Rock Cases)}

\section{Rowboat Cases}

\section{A. No Function:}

John is an accomplished woodworker and sailor, whose lifelong hobby is building rowboats by hand. He built his first rowboat — which he named "Drifter" - thirty years ago. Over the years there has been wear and tear, and it turns out that every single one of the original planks has needed to be replaced.

John — never one to throw anything out — has stored all of the original planks in his shed over the years. Last month John — realizing that he had accumulated enough old planks in his shed for a whole rowboat - took out his old plans for "Drifter" and assembled these planks exactly according to his old plans. John now has two rowboats of the same design: the rowboat originally built thirty years ago that has none of its original parts, and the rowboat just built one month ago with all of the original parts from "Drifter".

John has promised two of his friends - Suzy and Andy - that they can borrow Drifter for an outing. But Suzy and Andy aren't sure which of the two rowboats is actually Drifter. Andy thinks that the rowboat just built a month ago is actually Drifter, since it has exactly the same parts, arranged in exactly the same way as Drifter originally had. But Suzy thinks that the rowboat built thirty years ago with all of its parts completely replaced is actually Drifter, since, even though it has all new parts, this was just the result of normal maintenance.

\section{B. Replacement Preserves Function}

John is an accomplished woodworker and sailor, whose lifelong hobby is building rowboats by hand. He built his first rowboat — which he named "Drifter" - thirty years ago. It was an excellent rowboat: it was very stable, never let water in and sailed smoothly. Over the years there has been wear and tear, and so John, to keep it in perfect working order, has replaced various parts. And, it turns out that, over the years, every single one of the original planks has needed to be replaced.

John - never one to throw anything out — stored all of the original planks in his shed over the years. Last month John - realizing that he had accumulated enough old planks in his shed for a whole rowboat - took out his old plans for "Drifter" and assembled these planks exactly according to his old plans. This rowboat, however, worked terribly: it was very rickety, always let water in and sank after just a few minutes in the water. So, John now has two rowboats of the same design: the rowboat originally built thirty years ago that has none of its original parts and works perfectly as a rowboat, and the rowboat just built one month ago with all of the original parts from "Drifter", which works terribly as a rowboat.

John has promised two of his friends - Suzy and Andy - that they can borrow Drifter for an outing. But Suzy and Andy aren't sure which of the two rowboats is actually Drifter. Andy thinks that the rowboat just built a month ago is actually Drifter, since, even though it works 
terribly as a rowboat, it has exactly the same parts, arranged in exactly the same way as Drifter originally had. But Suzy disagrees. She thinks that the rowboat built thirty years ago with all of its parts completely replaced is actually Drifter, since even though it has all new parts, this was just the result of the normal maintenance required to keep the rowboat in perfect working order.

\section{Original Parts Preserves Function}

John is an accomplished woodworker and sailor, whose lifelong hobby is building rowboats by hand. He built his first rowboat — which he named "Drifter" - thirty years ago. It was an excellent rowboat: it was very stable, never let water in and sailed smoothly. But John was always thinking of ways to try and make the rowboat even better. And over the years, every single one of the original planks ended up being replaced. The end result, however, was not an improved rowboat. Rather the rowboat ended up being terrible: it was very rickety, always let water in and sank after just a few minutes in the water.

Fortunately, John — never one to throw anything out—stored all of the original planks in his shed over the years. Last month John — realizing that he had accumulated enough old planks in his shed for a whole rowboat - took out his old plans for "Drifter" and assembled these planks exactly according to his old plans. This rowboat worked perfectly: it was very stable, never let in water and sailed smoothly across the water. So, John now has two rowboats of the same design: the rowboat originally built thirty years ago that has none of its original parts and works terribly as a rowboat, and the rowboat just built one month ago with all of the original parts from "Drifter", which works perfectly as a rowboat.

John has promised two of his friends - Suzy and Andy - that they can borrow Drifter for an outing. But Suzy and Andy aren't sure which of the two rowboats is actually Drifter. Andy thinks that the rowboat just built a month ago is actually Drifter, since it has exactly the same parts, arranged in exactly the same way as Drifter originally had and works perfectly. But Suzy thinks that the rowboat built thirty years ago with all of its parts completely replaced is actually Drifter, since, even though it has all new parts and is a terrible rowboat, this was just the result of John's attempt to improve it.

\section{Comprehension Checks}

(1) The rowboat built a month ago is made from all the original parts of "Drifter". (Yes/No)

(2) The rowboat built thirty years ago has all new parts. (Yes/No)

(3) Suzy thinks that the rowboat built thirty years ago with all of its parts completely replaced is actually Drifter. (Yes/No)

(4) Andy thinks that the rowboat just built a month ago is actually Drifter. (Yes/No) 


\section{Organism Cases}

\section{A. No Function}

John is an accomplished biochemist who has devoted his life to studying organisms. When he first began his career thirty years ago, he discovered a new organism. He named the organism "Gollywag" and immediately logged the exact details of the organism. Over the years, John has conducted many experiments on the organism. Each time he conducts an experiment on the organism, he cuts off a part of it, which he uses for testing, and replaces it with the same type of part from another organism of the same type. Indeed, John has conducted so many experiments over the years that every single piece of the organism has been replaced.

After testing though, John always stores each part of the organism from the original organism. Last month John - realizing that he had accumulated enough parts of the organism for a whole organism - took out his logbook and assembled the parts exactly according to his notes. John now has two organisms of exactly the same design: the organism discovered thirty years ago with all of its parts completely replaced and the organism assembled just a month ago with all of the original parts from "Gollywag".

John has just hired two interns - Andy and Suzy — to work in his lab. He tells them that their first assignment will be to perform a series of experiments on "Gollywag". But, Suzy and Andy aren't sure which of the two organisms is actually Gollywag. Andy thinks that the organism assembled just a month ago is actually Gollywag, since it has exactly the same parts, arranged in exactly the same way as Gollywag originally had. But Suzy thinks that the organism discovered thirty years ago with all of its parts completely replaced is actually Gollywag, since, even though it has all new parts, this was just the result of years of experimentation.

\section{B. Replacement Preserves Function}

John is an accomplished biochemist who has devoted his life to studying organisms. When he first began his career thirty years ago, he discovered a new organism. He named the organism "Gollywag" and immediately logged the exact details of the organism.

John has always suffered from Eczema, a condition where, despite the use of lotions and so forth, his hands are itchy, dry and red. But, after first handling the organism, he noticed that his Eczema disappeared: his hands were no longer itchy, dry or red. So, he decided to start conducting experiments on the organism.

Over the years, John has conducted many experiments on the organism. Each time he conducts an experiment on the organism, he cuts off a part of it, which he uses for testing, and replaces it with the same type of part from another organism of the same type. Indeed, John has conducted so many experiments over the years that every single part of the organism has been replaced.

After testing though, John always stores each part from the original organism. Last month John — realizing that he had accumulated enough parts of the organism for a whole organismtook out his logbook and assembled the parts exactly according to his notes. When John handled 
this organism, however, he noticed his that his Eczema is severely aggravated: his hands were severely itchy, dry and red. So, John now has two organisms of exactly the same design: the organism discovered thirty years ago with all of its parts completely replaced which makes his Eczema completely disappear and the organism assembled just a month ago with all of the original parts from "Gollywag", which severely aggravates his Eczema.

John has just hired two interns-Andy and Suzy - to work in his lab. He tells them that their first assignment will be to perform a series of experiments on "Gollywag". But, Suzy and Andy aren't sure which of the two organisms is actually Gollywag. Andy thinks that the organism assembled just a month ago is actually Gollywag, since even though it severely aggravated John's Eczema, it has exactly the same parts, arranged in exactly the same way as Gollywag originally had. But Suzy thinks that the organism discovered thirty years ago with all of its parts completely replaced is actually Gollywag, since it makes John's Eczema disappear and even though it has all new parts, this was just the result of years of experimentation.

\section{Original Parts Preserves Function}

John is an accomplished biochemist who has devoted his life to studying organisms. When he first began his career thirty years ago, he discovered a new organism. He named the organism "Gollywag" and immediately logged the exact details of the organism.

John has always suffered from Eczema, a condition where, despite the use of lotions and so forth, his hands are itchy, dry and red. But, after first handling the organism, he noticed that his Eczema disappeared: his hands were no longer itchy, dry or red. So, he decided to start conducting experiments on the organism.

Over the years, John has conducted many experiments on the organism. Each time he conducts an experiment on the organism, he cuts off a part of it, which he uses for testing, and replaces it with the same type of part from another organism of the same type. Indeed, John has conducted so many experiments over the years that every single part of the organism has been replaced. In the end, however, John noticed that when he handled the organism that, instead of relieving his itchy, dry, red skin that it was actually severely aggravated: his hands were dryer, itchier and redder than they had ever been.

Fortunately, after testing, John always stores each part from the original organism. Last month John — realizing that he had accumulated enough parts of the organism for a whole organismtook out his logbook and assembled the parts exactly according to his notes. When John handled this organism, he noticed his Eczema completely disappeared: his hands were no longer itchy, dry or red. So, John now has two organisms of exactly the same design: the organism discovered thirty years ago with all of its parts completely replaced which severely aggravates his Eczema and the organism assembled just a month ago with all of the original parts from "Gollywag", which makes his Eczema completely disappear.

John has just hired two interns-Andy and Suzy — to work in his lab. He tells them that their first assignment will be to perform a series of experiments on "Gollywag". But, Suzy and Andy aren't sure which of the two organisms is actually Gollywag. Andy thinks that the organism 
assembled just a month ago is actually Gollywag, since it has exactly the same parts, arranged in exactly the same way as Gollywag originally had and makes John's Eczema completely disappear. But Suzy thinks that the organism discovered thirty years ago with all of its parts completely replaced is actually Gollywag, since, even though it has all new parts and severely aggravates John's Eczema, this was just the result of years of experimentation.

D. Comprehension Checks

(1) The organism assembled a month ago is made from all the original parts of "Gollywag".(Yes/No)

(2) The organism discovered thirty years ago has all new parts. (Yes/No)

(3) Suzy thinks that the organism discovered thirty years ago with all of its parts completely replaced is actually Gollywag. (Yes/No)

(4) Andy thinks that the organism assembled just a month ago is actually Gollywag. (Yes/No)

\section{Rock Cases}

\section{A. No Function}

John is an accomplished geochemist who has devoted his life to studying rocks. When he first began his career thirty years ago, he discovered a rock, made out of an unknown mineral. He named the rock "Zenyte" and immediately logged the exact details of the rock. Over the years, John has conducted many experiments on the rock. Each time he conducts an experiment on the rock, he breaks off a piece of it, which he uses for testing, and replaces it with the same type of mineral. Indeed, John has conducted so many experiments over the years that every single piece of the rock has been replaced.

After testing though, John always stores each piece of mineral from the original rock. Last month John - realizing that he had accumulated enough pieces of the mineral for a whole rocktook out his logbook and assembled the minerals exactly according to his notes. John now has two rocks of exactly the same design: the rock discovered thirty years ago with all of its minerals completely replaced and the rock assembled just a month ago with all of the original minerals from "Zenyte".

John has just hired two interns - Andy and Suzy — to work in his lab. He tells them that their first assignment will be to perform a series of experiments on "Zenyte". But, Suzy and Andy aren't sure which of the two rocks is actually Zenyte. Andy thinks that the rock assembled just a month ago is actually Zenyte, since it has exactly the same parts, arranged in exactly the same way as Zenyte originally had. But Suzy thinks that the rock discovered thirty years ago with all of its parts completely replaced is actually Zenyte, since, even though it has all new parts, this was just the result of years of experimentation. 


\section{B. Original Parts Preserves Function}

John is an accomplished geochemist who has devoted his life to studying rocks. When he first began his career thirty years ago, he discovered a rock, made out of an unknown mineral. He named the rock "Zenyte" and immediately logged the exact details of the rock.

John has always suffered from Eczema, a condition where, despite the use of lotions and so forth, his hands are itchy, dry and red. But, after first handling the rock, he noticed that his Eczema disappeared: his hands were no longer itchy, dry or red. So, he decided to start conducting experiments on the rock.

Over the years, John has conducted many experiments on the rock. Each time he conducts an experiment on the rock, he breaks off a piece of it, which he uses for testing, and replaces it with the same type of mineral. Indeed, John has conducted so many experiments over the years that every single piece of the rock has been replaced. In the end, however, John noticed that when he handled the rock that, instead of relieving his itchy, dry, red skin that it was actually severely aggravated: his hands were dryer, itchier and redder than they had ever been.

Fortunately, after testing, John always stores each piece of mineral from the original rock. Last month John — realizing that he had accumulated enough pieces of the mineral for a whole rocktook out his logbook and assembled the minerals exactly according to his notes. When John handled this rock, he noticed his Eczema completely disappeared: his hands were no longer itchy, dry or red. So, John now has two rocks of exactly the same design: the rock discovered thirty years ago with all of its minerals completely replaced which severely aggravates his Eczema and the rock assembled just a month ago with all of the original minerals from "Zenyte", which makes his Eczema completely disappear.

John has just hired two interns - Andy and Suzy - to work in his lab. He tells them that their first assignment will be to perform a series of experiments on "Zenyte". But, Suzy and Andy aren't sure which of the two rocks is actually Zenyte. Andy thinks that the rock assembled just a month ago is actually Zenyte, since it has exactly the same parts, arranged in exactly the same way as Zenyte originally had and makes John's Eczema completely disappear. But Suzy thinks that the rock discovered thirty years ago with all of its parts completely replaced is actually Zenyte, since, even though it has all new parts and severely aggravates John's Eczema, this was just the result of years of experimentation.

\section{Replacement Preserves Function}

John is an accomplished geochemist who has devoted his life to studying rocks. When he first began his career thirty years ago, he discovered a rock, made out of an unknown mineral. He named the rock "Zenyte" and immediately logged the exact details of the rock.

John has always suffered from Eczema, a condition where, despite the use of lotions and so forth, his hands are itchy, dry and red. But, after first handling the rock, he noticed that his Eczema disappeared: his hands were no longer itchy, dry or red. So, he decided to start conducting experiments on the rock. 
Over the years, John has conducted many experiments on the rock. Each time he conducts an experiment on the rock, he breaks off a piece of it, which he uses for testing, and replaces it with the same type of mineral. Indeed, John has conducted so many experiments over the years that every single piece of the rock has been replaced.

After testing though, John always stores each piece of mineral from the original rock. Last month John — realizing that he had accumulated enough pieces of the mineral for a whole rocktook out his logbook and assembled the minerals exactly according to his notes. When John handled this rock, however, he noticed his that his Eczema is severely aggravated: his hands were severely itchy, dry and red. So, John now has two rocks of exactly the same design: the rock discovered thirty years ago with all of its minerals completely replaced which makes his Eczema completely disappear and the rock assembled just a month ago with all of the original minerals from "Zenyte", which severely aggravates his Eczema.

John has just hired two interns - Andy and Suzy - to work in his lab. He tells them that their first assignment will be to perform a series of experiments on "Zenyte". But, Suzy and Andy aren't sure which of the two rocks is actually Zenyte. Andy thinks that the rock assembled just a month ago is actually Zenyte, since even though it severely aggravated John's Eczema, it has exactly the same parts, arranged in exactly the same way as Zenyte originally had. But Suzy thinks that the rock discovered thirty years ago with all of its parts completely replaced is actually Zenyte, since it makes John's Eczema disappear and even though it has all new parts, this was just the result of years of experimentation.

\section{Comprehension Checks}

(1) The rock assembled a month ago is made from all the original parts of "Zenyte".(Yes/No)

(2) The rock discovered thirty years ago has all new parts. (Yes/No)

(3) Suzy thinks that the rock discovered thirty years ago with all of its parts completely replaced is actually Zenyte. (Yes/No)

(4) Andy thinks that the rock assembled just a month ago is actually Zenyte. (Yes/No)

\section{Study 2 (Section 3.2: Rowboat, Organism and Rock Cases Modified)}

\section{Rowboat Cases}

\section{A. No Function}

John is an accomplished woodworker and sailor, whose lifelong hobby is building rowboats by hand. He built his first rowboat — which he named "Drifter" - thirty years ago. Over the years there has been wear and tear, and it turns out that every single one of the original planks has needed to be replaced. 
John — never one to throw anything out — has stored all of the original planks in his shed over the years. Last month John - realizing that he had accumulated enough old planks in his shed for a whole rowboat - took out his old plans for "Drifter" and assembled these planks exactly according to his old plans. John now has two rowboats of the same design: the rowboat originally built thirty years ago that has none of its original parts, and the rowboat just built one month ago with all of the original parts from "Drifter".

Two of John's friends - Suzy and Andy — are taking a painting class at the local university. Both of them decide that they would like to paint a picture of Drifter. They call John and he tells them that while he is an extremely private individual who never lets anyone mess with his stuff, he will make one exception for them. But he tells them that they can only paint Drifter and nothing else. He goes on to tell them though that he is heading out for vacation and will have no phone or internet access while he is away. But he tells them that they are free to stop by while he is away and paint Drifter.

So, one afternoon, Suzy and Andy head over to John's place so that they can begin their painting. But Suzy and Andy aren't sure which of the two rowboats is actually Drifter. Andy thinks that the rowboat just built a month ago is actually Drifter, since it has exactly the same parts, arranged in exactly the same way as Drifter originally had. But Suzy thinks that the rowboat built thirty years ago with all of its parts completely replaced is actually Drifter, since, even though it has all new parts, this was just the result of normal maintenance.

\section{B. Replacement Preserves Function}

John is an accomplished woodworker and sailor, whose lifelong hobby is building rowboats by hand. He built his first rowboat — which he named "Drifter" - thirty years ago. It was an excellent rowboat: it was very stable, never let water in and sailed smoothly. Over the years there has been wear and tear, and so John, to keep it in perfect working order, has replaced various parts. And, it turns out that, over the years, every single one of the original planks has needed to be replaced.

John - never one to throw anything out — stored all of the original planks in his shed over the years. Last month John - realizing that he had accumulated enough old planks in his shed for a whole rowboat - took out his old plans for "Drifter" and assembled these planks exactly according to his old plans. This rowboat, however, worked terribly: it was very rickety, always let water in and sank after just a few minutes in the water. So, John now has two rowboats of the same design: the rowboat originally built thirty years ago that has none of its original parts and works perfectly as a rowboat, and the rowboat just built one month ago with all of the original parts from "Drifter", which works terribly as a rowboat.

Two of John's friends - Suzy and Andy — are taking a painting class at the local university. Both of them decide that they would like to paint a picture of Drifter. They call John and he tells them that while he is an extremely private individual who never lets anyone mess with his stuff, he will make one exception for them. But he tells them that they can only paint Drifter and nothing 
else. He goes on to tell them though that he is heading out for vacation and will have no phone or internet access while he is away. But he tells them that they are free to stop by while he is away and paint Drifter.

So, one afternoon, Suzy and Andy head over to John's place so that they can begin their painting. But Suzy and Andy aren't sure which of the two rowboats is actually Drifter. Andy thinks that the rowboat just built a month ago is actually Drifter, since, even though it works terribly as a rowboat, it has exactly the same parts, arranged in exactly the same way as Drifter originally had. But Suzy disagrees. She thinks that the rowboat built thirty years ago with all of its parts completely replaced is actually Drifter, since even though it has all new parts, this was just the result of the normal maintenance required to keep the rowboat in perfect working order.

\section{Original Parts Preserves Function}

John is an accomplished woodworker and sailor, whose lifelong hobby is building rowboats by hand. He built his first rowboat — which he named "Drifter" - thirty years ago. It was an excellent rowboat: it was very stable, never let water in and sailed smoothly. But John was always thinking of ways to try and make the rowboat even better. And over the years, every single one of the original planks ended up being replaced. The end result, however, was not an improved rowboat. Rather the rowboat ended up being terrible: it was very rickety, always let water in and sank after just a few minutes in the water.

Fortunately, John — never one to throw anything out — stored all of the original planks in his shed over the years. Last month John - realizing that he had accumulated enough old planks in his shed for a whole rowboat - took out his old plans for "Drifter" and assembled these planks exactly according to his old plans. This rowboat worked perfectly: it was very stable, never let in water and sailed smoothly across the water. So, John now has two rowboats of the same design: the rowboat originally built thirty years ago that has none of its original parts and works terribly as a rowboat, and the rowboat just built one month ago with all of the original parts from "Drifter", which works perfectly as a rowboat.

Two of John's friends - Suzy and Andy — are taking a painting class at the local university. Both of them decide that they would like to paint a picture of Drifter. They call John and he tells them that while he is an extremely private individual who never lets anyone mess with his stuff, he will make one exception for them. But he tells them that they can only paint Drifter and nothing else. He goes on to tell them though that he is heading out for vacation and will have no phone or internet access while he is away. But he tells them that they are free to stop by while he is away and paint Drifter.

So, one afternoon, Suzy and Andy head over to John's place so that they can begin their painting. But Suzy and Andy aren't sure which of the two rowboats is actually Drifter. Andy thinks that the rowboat just built a month ago is actually Drifter, since it has exactly the same parts, arranged in exactly the same way as Drifter originally had and works perfectly. But Suzy thinks that the rowboat built thirty years ago with all of its parts completely replaced is actually Drifter, 
since, even though it has all new parts and is a terrible rowboat, this was just the result of John's attempt to improve it.

\section{Comprehension Checks}

(1) The rowboat built a month ago is made from all the original parts of "Drifter". (Yes/No)

(2) The rowboat built thirty years ago has all new parts. (Yes/No)

(3) Suzy thinks that the rowboat built thirty years ago with all of its parts completely replaced is actually Drifter. (Yes/No)

(4) Andy thinks that the rowboat just built a month ago is actually Drifter. (Yes/No)

\section{Organism Cases}

\section{A. No Function}

John is an accomplished microbiologist who has devoted his life to studying microorganisms. When he first began his career thirty years ago, he discovered a new microorganism. He named the microorganism "Gollywag" and immediately logged the exact details of the microorganism. Over the years, John has conducted many experiments on the microorganism. Each time he conducts an experiment on the microorganism, he cuts off a part of it, which he uses for testing, and replaces it with the same type of part from another microorganism of the same type. Indeed, John has conducted so many experiments over the years that every single piece of the microorganism has been replaced.

After testing though, John always stores each part of the microorganism from the original microorganism. Last month John - realizing that he had accumulated enough parts of the microorganism for a whole microorganism - took out his logbook and assembled the parts exactly according to his notes. John now has two microorganisms of exactly the same design: the microorganism discovered thirty years ago with all of its parts completely replaced and the microorganism assembled just a month ago with all of the original parts from "Gollywag".

John has just hired two interns - Andy and Suzy - to work in his lab. He tells them that their first assignment will be to perform a series of experiments on "Gollywag". But, Suzy and Andy aren't sure which of the two microorganisms is actually Gollywag. Andy thinks that the microorganism assembled just a month ago is actually Gollywag, since it has exactly the same parts, arranged in exactly the same way as Gollywag originally had. But Suzy thinks that the microorganism discovered thirty years ago with all of its parts completely replaced is actually Gollywag, since, even though it has all new parts, this was just the result of years of experimentation. 


\section{B. Replacement Preserves Function}

John is an accomplished microbiologist who has devoted his life to studying microorganisms. When he first began his career thirty years ago, he discovered a new microorganism. He named the microorganism "Gollywag" and immediately logged the exact details of the microorganism.

When John began examining the microorganism, he noticed it emitted a unique sequence of chemicals. Curious as to why the microorganism emitted this particular sequence of chemicals, John showed the microorganism to one of his friends, Frank, who is a biochemist. Frank kept the microorganism for several days and after careful examination he reported back to John. Frank told John that the microorganism is very delicate and can only survive if its body temperature stays between 60 and 65 degrees. Frank goes on to tell John that the way it maintains its body temperature is by having other microorganisms come into contact with it. And the only way to get the other microorganisms in contact with it is by emitting this unique sequence of chemicals. So, Frank tells John that the unique sequence of chemicals is actually for signaling to the others that they need to come into contact with it to help maintain its body temperature.

But John, being a microbiologist, isn't interested in the chemicals emitted by the microorganism. Rather he is interested in investigating and studying the various parts of the microorganism "Gollywag". So, he starts conducting experiments on the microorganism.

Over the years, John has conducted many experiments on the microorganism. Each time he conducts an experiment on the microorganism, he cuts off a part of it, which he uses for testing, and replaces it with the same type of part from another microorganism of the same type. Indeed, John has conducted so many experiments over the years that every single part of the microorganism has been replaced.

After testing though, John always stores each part from the original microorganism. Last month John - realizing that he had accumulated enough parts of the microorganism for a whole microorganism - took out his logbook and assembled the parts exactly according to his notes. When John handled this microorganism, however, he noticed his that it no longer emitted the unique sequence of chemicals. So, John now has two microorganisms of exactly the same design: the microorganism discovered thirty years ago with all of its parts completely replaced and which emits the unique sequence of chemicals and the microorganism assembled just a month ago with all of the original parts from "Gollywag", which no longer emits the unique sequence of chemicals.

John has just hired two interns - Andy and Suzy — to work in his lab. He tells them that their first assignment will be to perform a series of experiments on "Gollywag". But, Suzy and Andy aren't sure which of the two microorganisms is actually Gollywag. Andy thinks that the microorganism assembled just a month ago is actually Gollywag, since even though it does not emit the unique sequence of chemicals, it has exactly the same parts, arranged in exactly the same way as Gollywag originally had. But Suzy thinks that the microorganism discovered thirty 
years ago with all of its parts completely replaced is actually Gollywag, since it emits the unique sequence of chemicals, and even though it has all new parts, this was just the result of years of experimentation.

\section{Original Parts Preserves Function}

John is an accomplished microbiologist who has devoted his life to studying microorganisms. When he first began his career thirty years ago, he discovered a new microorganism. He named the microorganism "Gollywag" and immediately logged the exact details of the microorganism.

When John began examining the microorganism, he noticed it emitted a unique sequence of chemicals. Curious as to why the microorganism emitted this particular sequence of chemicals, John showed the microorganism to one of his friends, Frank, who is a biochemist. Frank kept the microorganism for several days and after careful examination he reported back to John. Frank told John that the microorganism is very delicate and can only survive if its body temperature stays between 60 and 65 degrees. Frank goes on to tell John that the way it maintains its body temperature is by having other microorganisms come into contact with it. And the only way to get the other microorganisms in contact with it is by emitting this unique sequence of chemicals. So, Frank tells John that the unique sequence of chemicals is actually for signaling to the others that they need to come into contact with it to help maintain its body temperature.

But John, being a microbiologist, isn't interested in the chemicals emitted by the microorganism. Rather he is interested in investigating and studying the various parts of the microorganism "Gollywag". So, he starts conducting experiments on the microorganism.

Over the years, John has conducted many experiments on the microorganism. Each time he conducts an experiment on the microorganism, he cuts off a part of it, which he uses for testing, and replaces it with the same type of part from another microorganism of the same type. Indeed, John has conducted so many experiments over the years that every single part of the microorganism has been replaced. In the end, however, John noticed that when he examined the microorganism it no longer emitted the unique sequence of chemicals.

After testing though, John always stores each part from the original microorganism. Last month John — realizing that he had accumulated enough parts of the microorganism for a whole microorganism - took out his logbook and assembled the parts exactly according to his notes. When John examined this microrganism, he noticed that it emitted the unique sequence of chemicals. So, John now has two organisms of exactly the same design: the microorganism discovered thirty years ago with all of its parts completely replaced which no longer emits the unique sequence of chemicals and the microorganism assembled just a month ago with all of the original parts from "Gollywag", which emits the unique sequence of chemicals.

John has just hired two interns - Andy and Suzy — to work in his lab. He tells them that their first assignment will be to perform a series of experiments on "Gollywag". But, Suzy and Andy aren't sure which of the two microorganisms is actually Gollywag. Andy thinks that the microorganism assembled just a month ago is actually Gollywag, since it has exactly the same 
parts, arranged in exactly the same way as Gollywag originally had and emits the unique sequence of chemicals. But Suzy thinks that the microorganism discovered thirty years ago with all of its parts completely replaced is actually Gollywag, since, even though it has all new parts and no longer emits the unique sequence of chemicals, this was just the result of years of experimentation.

\section{Comprehension Checks}

(1) The microorganism assembled a month ago is made from all the original parts of "Gollywag".(Yes/No)

(2) The microorganism discovered thirty years ago has all new parts. (Yes/No)

(3) Suzy thinks that the microorganism discovered thirty years ago with all of its parts completely replaced is actually Gollywag. (Yes/No)

(4) Andy thinks that the microorganism assembled just a month ago is actually Gollywag. (Yes/No)

\section{Rock Cases}

\section{A. No Function}

John is an accomplished geochemist who has devoted his life to studying rocks. When he first began his career thirty years ago, he discovered a rock, made out of an unknown mineral. And interestingly, due to this mineral, the rock took on a distinctive, hollowed-out seashell shape. He named the rock "Zenyte" and immediately logged the exact details of the rock.

Over the years, John has conducted many experiments on the rock. Each time he conducts an experiment on the rock, he breaks off a piece of it, which he uses for testing, and replaces it with the same type of mineral. Indeed, John has conducted so many experiments over the years that every single piece of the rock has been replaced.

After testing though, John always stores each piece of mineral from the original rock. Last month John — realizing that he had accumulated enough pieces of the mineral for a whole rocktook out his logbook and assembled the minerals exactly according to his notes. John now has two rocks of exactly the same design: the rock discovered thirty years ago with all of its minerals completely replaced and the rock assembled just a month ago with all of the original minerals from "Zenyte".

John has just hired two interns - Andy and Suzy — to work in his lab. He tells them that their first assignment will be to perform a series of experiments on "Zenyte". But, Suzy and Andy aren't sure which of the two rocks is actually Zenyte. Andy thinks that the rock assembled just a month ago is actually Zenyte, since it has exactly the same parts, arranged in exactly the same way as Zenyte originally had. But Suzy thinks that the rock discovered thirty years ago with all 
of its parts completely replaced is actually Zenyte, since, even though it has all new parts, this was just the result of years of experimentation.

\section{B. Replacement Preserves Function}

John is an accomplished geochemist who has devoted his life to studying rocks. When he first began his career thirty years ago, he discovered a rock, made out of an unknown mineral. And interestingly, due to this mineral, the rock took on a distinctive, hollowed-out seashell shape. He named the rock "Zenyte" and immediately logged the exact details of the rock.

When John began examining the rock, he noticed that the rock housed an interesting species of worm. Since he had never seen this particular type of worm before, John showed the rock to one of his friends, Frank, who is a biologist. Frank kept the rock for several days and after careful examination he reported back to John. Frank told John that the worms living in the rock are actually very delicate. Indeed, Frank told John that the rock actually creates the perfect conditions for the worms to breed and flourish in and that there is no other environment in which the worms could survive. So, Frank tells John that the rock is actually for providing a perfectly hospitable environment for the worms.

But John, being a geochemist, isn't interested in the worms. Rather he is interested in investigating and studying the unknown mineral that makes up "Zenyte". So, he starts conducting experiments on the rock.

Over the years, John has conducted many experiments on the rock. Each time he conducts an experiment on the rock, he breaks off a piece of it, which he uses for testing, and replaces it with the same type of mineral. Indeed, John has conducted so many experiments over the years that every single piece of the rock has been replaced.

After testing though, John always stores each piece of mineral from the original rock. Last month John - realizing that he had accumulated enough pieces of the mineral for a whole rocktook out his logbook and assembled the minerals exactly according to his notes. When John examined this rock, however, he noticed that all the worms died. So, John now has two rocks of exactly the same design: the rock discovered thirty years ago with all of its minerals completely replaced which creates a perfectly hospitable environment for the worms to reproduce and flourish and the rock assembled just a month ago with all of the original minerals from "Zenyte", which kills all the worms.

John has just hired two interns - Andy and Suzy — to work in his lab. He tells them that their first assignment will be to perform a series of experiments on "Zenyte". But, Suzy and Andy aren't sure which of the two rocks is actually Zenyte. Andy thinks that the rock assembled just a month ago is actually Zenyte, since even though it kills the worms, it has exactly the same parts, arranged in exactly the same way as Zenyte originally had. But Suzy thinks that the rock discovered thirty years ago with all of its parts completely replaced is actually Zenyte, since it creates a perfectly hospitable environment for the worms to reproduce and flourish and even though it has all new parts, this was just the result of years of experimentation. 


\section{Original Parts Preserves Function}

John is an accomplished geochemist who has devoted his life to studying rocks. When he first began his career thirty years ago, he discovered a rock, made out of an unknown mineral. And interestingly, due to this mineral, the rock took on a distinctive, hollowed-out seashell shape. He named the rock "Zenyte" and immediately logged the exact details of the rock.

When John began examining the rock, he noticed that the rock housed an interesting species of worm. Since he had never seen this particular type of worm before, John showed the rock to one of his friends, Frank, who is a biologist. Frank kept the rock for several days and after careful examination he reported back to John. Frank told John that the worms living in the rock are actually very delicate. Indeed, Frank told John that the rock actually creates the perfect conditions for the worms to breed and flourish in and that there is no other environment in which the worms could survive. So, Frank tells John that the rock is actually for providing a perfectly hospitable environment for the worms.

But John, being a geochemist, isn't interested in the worms. Rather he is interested in investigating and studying the unknown mineral that makes up "Zenyte". So, he starts conducting experiments on the rock.

Over the years, John has conducted many experiments on the rock. Each time he conducts an experiment on the rock, he breaks off a piece of it, which he uses for testing, and replaces it with the same type of mineral. Indeed, John has conducted so many experiments over the years that every single piece of the rock has been replaced. In the end, however, John noticed that the worms could no longer survive in the rock.

After testing though, John always stores each piece of mineral from the original rock. Last month John — realizing that he had accumulated enough pieces of the mineral for a whole rocktook out his logbook and assembled the minerals exactly according to his notes. When John examined this rock, he noticed that the worms reproduced and flourished. So, John now has two rocks of exactly the same design: the rock discovered thirty years ago with all of its minerals completely replaced which kills all the worms and the rock assembled just a month ago with all of the original minerals from "Zenyte", which creates a perfectly hospitable environment for the worms to reproduce and flourish.

John has just hired two interns - Andy and Suzy — to work in his lab. He tells them that their first assignment will be to perform a series of experiments on "Zenyte". But, Suzy and Andy aren't sure which of the two rocks is actually Zenyte. Andy thinks that the rock assembled just a month ago is actually Zenyte, since it has exactly the same parts, arranged in exactly the same way as Zenyte originally had and creates a hospitable environment for the worms to reproduce and flourish. But Suzy thinks that the rock discovered thirty years ago with all of its parts completely replaced is actually Zenyte, since, even though it has all new parts and kills all the worms, this was just the result of years of experimentation. 


\section{Comprehension Checks}

(1) The rock assembled a month ago is made from all the original parts of "Zenyte".(Yes/No)

(2) The rock discovered thirty years ago has all new parts. (Yes/No)

(3) Suzy thinks that the rock discovered thirty years ago with all of its parts completely replaced is actually Zenyte. (Yes/No)

(4) Andy thinks that the rock assembled just a month ago is actually Zenyte. (Yes/No)

\section{Study 3 (Section 3.3: Rock Smashed Into Three Pieces)}

\section{A. Loss of Function}

John is out hiking and he spots something glowing in a strange way by the side of the trail. It turns out to be a rock, glowing because it serves as a home to a special sort of microorganism. John takes the thing home to study it further. But it begins to fade as the microorganisms it hosts start dying. John realizes that the microorganisms are feeding on minerals in the rock but can't access the minerals in the interior of the rock. So he tries an experiment: he hits the rock with a hammer, breaking it into three pieces. But the experiment does not work: the microorganisms all begin quickly dying and it stops glowing, fading completely to black.

\section{B. And Preservation of Function:}

John is out hiking and he spots something glowing in a strange way by the side of the trail. It turns out to be a rock, glowing because it serves as a home to a special sort of microorganism. John takes the thing home to study it further. But it begins to fade as the microorganisms it hosts start dying. John realizes that the microorganisms are feeding on minerals in the rock but can't access the minerals in the interior of the rock. So he tries an experiment: he hits the rock with a hammer, breaking it into three pieces. The experiment works: the microorganisms are then able to access all the minerals and so it resumes glowing even brighter than before.

\section{Study 4 (Section 3.4: Denting and Pulverizing)}

\section{A. Denting}

John is out hiking and he spots something glowing in a strange way by the side of the trail. It turns out to be a rock, glowing because it serves as a home to a special sort of microorganism. John takes the thing home to study it further. But it begins to fade as the microorganisms it hosts start dying. John realizes that the microorganisms are feeding on minerals in the rock but can't access the minerals in the interior of the rock. So he tries an experiment: he hits the rock with a hammer. As a result the rock is dented. But the experiment does not work: the microorganisms all begin quickly dying and it stops glowing, fading completely to black. 


\section{B. Denting Control}

John is out hiking and he spots something by the side of the trail. It turns out to be a rock. He takes the thing home. Later that evening, John gets bored and he hits it with a hammer. As a result, the rock is dented.

\section{Pulverizing}

John is out hiking and he spots something glowing in a strange way by the side of the trail. It turns out to be a rock, glowing because it serves as a home to a special sort of microorganism. John takes the thing home to study it further. But it begins to fade as the microorganisms it hosts start dying. John realizes that the microorganisms are feeding on minerals in the rock but can't access the minerals in the interior of the rock. So he tries an experiment: he smashes the rock into pieces with a hammer. The experiment works: the microorganisms are then able to access all the minerals and so it resumes glowing even brighter than before.

\section{Pulverizing Control}

John is out hiking and he spots something by the side of the trail. It turns out to be a rock. He takes the thing home. Later that evening John gets bored and he smashes it into pieces with a hammer.

\section{Study 5 (Section 3.5: Denting and Pulverizing with Loss and Preservation of Function)}

\section{A. Denting, Loss of Function}

John is a geologist. Recently, he went on an expedition to Antarctica in search of new kinds of rocks. While in Antarctica, John discovered a very strange rock, unlike any rock he had ever seen, and noticed what appeared to be tiny worms in the crevices of the rock. He named the rock "Zenyte".

John took Zenyte back to Arizona and gave it to a biologist, Frank. Frank kept Zenyte for several days and after careful examination he reported back to John. Frank told John that the worms living in Zenyte are actually very delicate. Indeed, Frank told John that Zenyte actually transmits an incredibly rare combination of chemicals and that this combination of chemicals creates the perfect conditions for the worms to breed and flourish. Frank tells John that there is no other environment in which the worms could survive and that Zenyte is actually for providing a perfectly hospitable environment for the worms.

Frank kept Zenyte so that he could continue studying the worms. But as time went on, Frank noticed that Zenyte was reacting negatively to the lab environment and so was getting denser. As Zenyte became denser the combination of chemicals transmitted by it were slowly decreasing and the worms were beginning to die.

In an attempt to preserve Zentye and prevent the worms from dying, Frank decided that he would hit the rock with a hammer. As a result, the rock is dented and, unfortunately, now the combination of chemicals is not transmitted at all and the worms are all quickly dying. 
Later that day, John wants to examine Zenyte and so goes to Frank's lab. John asks Frank if he can examine Zenyte and Frank takes him over to it. When John looks at it, he says "this is not Zenyte, you've completely destroyed it and it no longer performs the functions that are essential to it: it no longer transmits the combination of chemicals and all the worms it once housed are dead". But Frank disagrees, saying that though it looks different it is still Zenyte.

B. Denting, Preservation of Function

John is a geologist. Recently, he went on an expedition to Antarctica in search of new kinds of rocks. While in Antarctica, John discovered a very strange rock, unlike any rock he had ever seen, and noticed what appeared to be tiny worms in the crevices of the rock. He named the rock "Zenyte".

John took Zenyte back to Arizona and gave it to a biologist, Frank. Frank kept Zenyte for several days and after careful examination he reported back to John. Frank told John that the worms living in Zenyte are actually very delicate. Indeed, Frank told John that Zenyte actually transmits an incredibly rare combination of chemicals and that this combination of chemicals creates the perfect conditions for the worms to breed and flourish. Frank tells John that there is no other environment in which the worms could survive and that Zenyte is actually for providing a perfectly hospitable environment for the worms.

Frank kept Zenyte so that he could continue studying the worms. But as time went on, Frank noticed that Zenyte was reacting negatively to the lab environment and so was getting denser. As Zenyte became denser the combination of chemicals transmitted by it were slowly decreasing and the worms were beginning to die.

In an attempt to preserve Zentye and prevent the worms from dying, Frank decided that he would hit the rock with a hammer. As a result, the rock is dented and now, the combination of chemicals is being perfectly transmitted - just like they were before Zenyte became dense — and the worms are continuing to flourish.

Later that day, John wants to examine Zenyte and so goes to Frank's lab. John asks Frank if he can examine Zenyte and Frank takes him over to it. When John looks at it, he says "this is not Zenyte, you've completely destroyed it". But Frank disagrees, saying that it is still Zenyte. He tells John that though it looks different, it performs all of the functions that are essential to it: it still transmits the rare combination of chemicals and still creates a perfectly hospitable environment for the worms.

\section{Pulverizing, Loss of Function}

John is a geologist. Recently, he went on an expedition to Antarctica in search of new kinds of rocks. While in Antarctica, John discovered a very strange rock, unlike any rock he had ever seen, and noticed what appeared to be tiny worms in the crevices of the rock. He named the rock "Zenyte". 
John took Zenyte back to Arizona and gave it to a biologist, Frank. Frank kept Zenyte for several days and after careful examination he reported back to John. Frank told John that the worms living in Zenyte are actually very delicate. Indeed, Frank told John that Zenyte actually transmits an incredibly rare combination of chemicals and that this combination of chemicals creates the perfect conditions for the worms to breed and flourish. Frank tells John that there is no other environment in which the worms could survive and that Zenyte is actually for providing a perfectly hospitable environment for the worms.

Frank kept Zenyte so that he could continue studying the worms. But as time went on, Frank noticed that Zenyte was reacting negatively to the lab environment and so was getting denser. As Zenyte became denser the combination of chemicals transmitted by it were slowly decreasing and the worms were beginning to die.

In an attempt to preserve Zentye and prevent the worms from dying, Frank decided that he would carefully break up the rock. He breaks Zenyte into more fine grained pieces until the pieces are so small - much like dust particles - that he cannot break them down any further. Unfortunately, now the combination of chemicals is not transmitted at all and the worms are all quickly dying.

Later that day, John wants to examine Zenyte and so goes to Frank's lab. John asks Frank if he can examine Zenyte and Frank takes him over to it. When John looks at it, he says "this is not Zenyte, you've completely destroyed it and it no longer performs the functions that are essential to it: it no longer transmits the combination of chemicals and all the worms it once housed are dead". But Frank disagrees, saying that though it looks different it is still Zenyte.

\section{Pulverizing, Preservation of Function}

John is a geologist. Recently, he went on an expedition to Antarctica in search of new kinds of rocks. While in Antarctica, John discovered a very strange rock, unlike any rock he had ever seen, and noticed what appeared to be tiny worms in the crevices of the rock. He named the rock "Zenyte".

John took Zenyte back to Arizona and gave it to a biologist, Frank. Frank kept Zenyte for several days and after careful examination he reported back to John. Frank told John that the worms living in Zenyte are actually very delicate. Indeed, Frank told John that Zenyte actually transmits an incredibly rare combination of chemicals and that this combination of chemicals creates the perfect conditions for the worms to breed and flourish. Frank tells John that there is no other environment in which the worms could survive and that Zenyte is actually for providing a perfectly hospitable environment for the worms.

Frank kept Zenyte so that he could continue studying the worms. But as time went on, Frank noticed that Zenyte was reacting negatively to the lab environment and so was getting denser. As Zenyte became denser the combination of chemicals transmitted by it were slowly decreasing and the worms were beginning to die.

In an attempt to preserve Zentye and prevent the worms from dying, Frank decided that he would carefully break up the rock. As he breaks Zenyte into more fine grained pieces he notices that the chemical transmission is slowly being restored to normal levels. So, he continues until the 
pieces are so small — much like dust particles - that he cannot break them down any further. Now, the combination of chemicals is being perfectly transmitted-just like they were before Zenyte became dense - and the worms are continuing to flourish.

Later that day, John wants to examine Zenyte and so goes to Frank's lab. John asks Frank if he can examine Zenyte and Frank takes him over to it. When John looks at it, he says "this is not Zenyte, you've completely destroyed it". But Frank disagrees, saying that it is still Zenyte. He tells John that though it looks different, it performs all of the functions that are essential to it: it still transmits the rare combination of chemicals and still creates a perfectly hospitable environment for the worms.

\section{Study 6 (Footnote 13: Ownership and Function)}

\section{A. Same Owner, Preserves Function}

One day while mowing, John discovered a rock in his backyard which was glowing in a strange way. After studying the rock he realized that it was glowing because it serves as a home to some special microorganisms which feed on the minerals in the rock.

After keeping the rock in his house for a year, John decides that he does not want the rock in his house anymore. He considers giving it to his neighbor Frank but instead decides that he'd rather keep it for himself. Since he wants to keep it but doesn't want it in his house, he decides to just throw it in his backyard so he can enjoy it when he is mowing.

The rock now glows even brighter than before and the microorganisms flourish as they continue to feed on the minerals in the rock

\section{B. Same Owner, Loses Function}

One day while mowing, John discovered a rock in his backyard which was glowing in a strange way. After studying the rock he realized that it was glowing because it serves as a home to some special microorganisms which feed on the minerals in the rock.

After keeping the rock in his house for a year, John decides that he does not want the rock in his house anymore. He considers giving it to his neighbor Frank but instead decides that he'd rather keep it for himself. Since he wants to keep it but doesn't want it in his house, he decides to just throw it in his backyard so he can enjoy it when he is mowing.

The rock, however, stops glowing and the microorganisms it hosts begin dying.

\section{Different Owner, Preserves Function}


One day while mowing, John discovered a rock in his backyard which was glowing in a strange way. After studying the rock he realized that it was glowing because it serves as a home to some special microorganisms which feed on the minerals in the rock.

After keeping the rock in his house for a year, John decides that he does not want the rock anymore. He decides to give it to his neighbor Frank. To surprise him, John decides that he'll throw it in Frank's front yard so that he'll see it when he gets the morning paper. So, he throws the rock in Frank's front yard. The rock now glows even brighter than before and the microorganisms flourish as they continue to feed on the minerals in the rock.

The next morning Frank finds the rock when he gets the paper. He picks it up and decides to take it inside his house to display over his fireplace.

\section{Different Owner, Loses Function}

One day while mowing, John discovered a rock in his backyard which was glowing in a strange way. After studying the rock he realized that it was glowing because it serves as a home to some special microorganisms which feed on the minerals in the rock.

After keeping the rock in his house for a year, John decides that he does not want the rock anymore. He decides to give it to his neighbor Frank. To surprise him, John decides that he'll throw it in Frank's front yard so that he'll see it when he gets the morning paper. So, he throws the rock in Frank's front yard. The rock, however, stops glowing and the microorganisms it hosts begin dying.

The next morning Frank finds the rock when he gets the paper. He picks it up and decides to take it inside his house to display over his fireplace.

\section{E. Probe}

Is the rock that [Frank/John] now has really the same rock that John originally found in his backyard?

$1=$ No it is different, $7=$ Yes, it is the same

\section{F. Results}

There was a large-sized effect of whether the rock lost $(\mathrm{M}=4.71, \mathrm{SD}=2.16)$ or preserved $(\mathrm{M}=6.49, \mathrm{SD}=.971)$ its function on persistence judgments $\mathrm{F}(1,137)=40.99, \mathrm{p}<.001, \mathrm{np} 2=.230$. There was no effect of whether John $(\mathrm{M}=5.63, \mathrm{SD}=1.89)$ or Frank $(\mathrm{M}=5.71, \mathrm{SD}=1.82)$ owned the rock, $\mathrm{F}(1,137)=.002, \mathrm{p}=.967$ and no interaction between ownership and function $\mathrm{F}(1$, 137) $=.054, \mathrm{p}=.816$ 
